\title{
Determinants of Tree Sway Frequency in Temperate Deciduous Forests of the Northeast United States
}

Amanda Bunce

amanda.bunce@uconn.edu

\section{Recommended Citation}

Bunce, Amanda, "Determinants of Tree Sway Frequency in Temperate Deciduous Forests of the Northeast United States" (2017). Master's Theses. 1126.

https://opencommons.uconn.edu/gs_theses/1126 


\title{
Determinants of Tree Sway Frequency in Temperate Deciduous Forests of the Northeast
} United States

\author{
Amanda Bunce \\ B.A. Central Connecticut State University, 2007
}

\author{
A thesis \\ submitted in partial fulfillment \\ of the requirements for the degree of Master of Science \\ at the University of Connecticut, 2017
}


Copyright by

Amanda Bunce

2017

ii. 
Approval Page

Master of Science Thesis

\section{Determinants of Tree Sway Frequency in Temperate Deciduous Forests of the Northeast United States}

Presented by

Amanda Bunce, B.A.

Major Advisor

John C. Volin, Univ. of Connecticut

Associate Advisor

Mark Rudnicki, Michigan Tech. Univ.

Associate Advisor

Thomas E. Worthley, Univ. of Connecticut

Associate Advisor

David R. Miller, Univ. of Connecticut

Associate Advisor

Jason Parent, Univ. of Connecticut

University of Connecticut

2017

iii. 


\section{Acknowledgements}

Funding for this research have been provided by the University of Connecticut's Department of Natural Resources and the Environment, the Eversource Energy Center. Other contributors of resources include The United Illuminating Company, The Litchfield County Extension Center in Torrington, the Regional Water Company of southern CT, and DOT garage \#1513 in Orange.

My committee members deserve an enthusiastic shout out for the time and effort they spent bringing this project to fruition. I'd like to thank Mark and John for the opportunities they gave me and their faith in me. My sincerest gratitude also goes out to Jason, Tom and Dave for their consistent patience, consultations and help, without which none of this would have come together.

In addition to my committee members, the community of faculty and students in and around the NRE department has been essential to this project along every step of the way. I would like to thank professors Tom Meyer and Bob Fahey; all of the NRE, Engineering, and Eversource folks involved with the Eversource Energy Center; UCONN's statistical consulting team; Danielle and the Natural Resources Dept. Writing Club; Nancy and Ptero, Bailey McNichol and the UCONN Forest Crew members from 2014 to 2017: Mike Heyn, Brandon, Cherico, Tom the younger, Meg, Andrew, Carl, Ryan, Taylor (1), Taylor (2), Nick, Mike, Sophia, David, Lauren, Izzy, Dwayne, Tanner, Travis, Clay and Alana.

I would also like to thank my family and friends for encouraging me and putting up with all the exciting tree facts that I needed to pass on to them. Thanks to my mom, ever my inspiration, and thanks to my dad for tossing me into the world of working forests. Thanks, Corey, for always helping me put the science in perspective, and Caitlin, thanks for your perspectives too. Thanks, Molly, Midas, Justin, Thea and Dave, Tyler, Dr. Bethany, Tim and Jeph for hiking with me:-) 


\section{Table of Contents}

1.0 Introduction and Background p. 1

1.1 Trees, Power and the Population p. 1

$\begin{array}{ll}\text { 1.2 The Study of Tree-Wind Interaction } & \text { p. } 3\end{array}$

1.2.1 Drivers of Fundamental Vibrational Frequency p. 5

2.0 Study Design and Methodology

p. 10

2.1 Study Sites

p. 10

2.2 Instrumentation

p. 10

2.3 Variables

p. 17

2.3.1 Dependent Variables

p. 19

2.3.2 Predictor Variables

p. 19

2.4 Statistical Analysis

p. 25

p. 27

p. 27

3.1 Environmental Variables

p. 27

3.1.1 Foliage On/Off and Temperatures Above/Below Freezing

p. 27

3.1.2 Wind Speed

p. 38

3.1.4 Shelter and Support

p. 42

p. 48

3.2 Reduction of the Dataset

p. 48

3.3 Surrounding Forest Structure Variables

p. 48

3.4 Tree Architecture Variables

3.4.1 Height, Diameter at Breast Height, Slenderness

p. 48

3.4.2 Species, Young's Modulus of Elasticity

p. 52 and the Cantilever Parameter

3.4.3 Crown parameters p. 56

3.5 Final Model

p. 59

p. 60

$\begin{array}{ll}\text { 4.1 Foliage Condition and Freezing Temperatures } & \text { p. } 60 \\ \text { 4.2 Wind Speed and Fluctuation in Speed } & \text { p. } 60\end{array}$

4.3 Shelter and Support

p. 62

4.4 Surrounding Forest Structure

p. 63

4.5 Tree Architecture Parameters

p. 64

4.6 Forest Management Implications

p. 66

4.7 Future Directions

p. 68

5.0 Conclusion

p. 69

6.0 Resources

p. 70 


\title{
Determinants of Tree Sway Frequency in Temperate Deciduous Forests of the Northeast United States
}

\author{
Amanda Bunce, MS \\ University of Connecticut, 2017
}

Trees are the most common cause of utility damage and power outages during storms in the northeastern United States. Previous studies on tree sway and risk-of-wind-throw have largely been conducted in heavily managed, even-aged, monospecific coniferous stands, while relatively little is known for northeastern mixed temperate deciduous forests. Past studies have suggested a relationship of fundamental vibrational frequencies (FVF) to wind-firmness. The objective of this study was to identify factors determining tree sway frequency in temperate deciduous forests from characteristics of tree architecture, stand structure and wind conditions. To this end, the motion of 41 trees across nine different species from three sites in southern New England was monitored. Their FVF were calculated and regressed against a number of potential predictor variables to create a predictive model for FVF.

Results showed that significant predictors included a calculation of slenderness that has been found to predict FVF in studies on coniferous trees, namely diameter at breast height (DBH) divided by tree height squared $\left(\mathrm{H}^{2}\right)$, as well as environmental variables accounting for the presence or absence of leaves and temperatures above or below freezing. The results of this study highlight the importance of tree shape in predicting FVF, and tree shape forms similarly (tall slender trunks) in a closed canopy forest succession situation regardless of species mix or location. This relationship of FVF to an attribute that can be managed for, such as $\mathrm{DBH} \cdot \mathrm{H}^{-2}$, may help to mitigate tree-related storm damage to utility infrastructure. 


\subsection{Introduction}

\subsection{Trees, Power and the Population}

Trees are widely accepted as the most common threat to utility lines (Cieslewicz \& Novembri, 2004). Contact between trees and power lines is the cause of the majority of electrical outages during storms, as well as a significant cause of wildfires (Cieslewicz \& Novembri, 2004). It has been estimated that up to $40 \%$ of power outages in the U.S. are due to vegetation and cost more than $\$ 120$ billion annually (Deric \& Hollenbaugh, 2003). Widespread damage to power lines from vegetation is particularly conspicuous in the northeastern U.S. The southern New England states, Rhode Island, Connecticut and Massachusetts, are the 4th, 5th and 6th most densely populated (US Census, 2010), respectively. They are also noted for their dense forest cover ranging from 54 to $64 \%$ of their area (Nowak \& Greenfield, 2008; Wilson et al. 2015). While tree-fall is a natural occurrence in forests, the current forest structure found in southern New England is more susceptible to storm damage as a result of centuries of human activity. That condition, in combination with the dense human population creates a situation particularly conducive to tree-caused utility damage.

Prior to European colonization, the forest was expansive and contiguous across the northeastern U.S. (Bromley, 1935). Beginning in the early $17^{\text {th }}$ century, the southern New England forests were widely cleared by colonists, first for pasture and agricultural fields, and later, in the $19^{\text {th }}$ century for industrial uses (Foster, 1992). In the late $19^{\text {th }}$ and early $20^{\text {th }}$ century, forests began growing back from abandoned fields and cut over woodlots (Foster, 1992) and in the 1930's an estimated 60\% of the land was brush and young forest (Bromley, 1935). As a result, much of the temperate deciduous forest in southern New England today is highly fragmented, and made of large trees with a dense, even-aged structure (Butler et al., 2011). 
Coincident with the increasing forest cover in the $20^{\text {th }}$ century was an increase in the human population in southern New England, from 4.9 million in 1910 to 11 million in 2010 (US Census, 2010). Human activity has impacted the composition, structure and ecological function of temperate deciduous forests. Impacts include the introduction of invasive pests and pathogens. The once dominant deciduous tree species, the American chestnut (Castanea dentata), was decimated throughout its range in just a few decades by the introduction of a nonindigenous fungus, chestnut blight (Cryphonectria parasitica) (Paillet, 2002). Introduced destructive pests and pathogens continue to threaten and alter the forest today (Butler et al., 2011; Lovett et al., 2006). In addition, the impact of parcelization and development has led to widespread forest fragmentation; $49 \%$ of forested land in southern New England is within 300 feet of development or agriculture (Butler et al., 2011). Fragmentation increases edges, where vegetation is subject to greater stresses including more extreme shifts in temperature, light and moisture, exposure to pollutants including road salt, and pressure from certain pests and competitive exotic species (Saunders et al., 1991; Murcia, 1995). Competition for light also drives edge trees to grow tall and thin and reach out into open spaces in the canopy for light, which often means over roads, fields or powerline corridors creating a "cantilevered edge" (Murcia, 1995). Cantilevered edge trees can modulate edge effects (Murcia, 1995), but their crowns tend to be asymmetrical and unbalanced, and stems can be leaning. Further stresses on structurally compromised trees, such as those on cantilevered edges, include the increasing frequency of flooding, severity of drought (Trenberth, 2011) and intensity of storm events, commonly attributed to human-induced climate change (Emanuel, 2005; Webster, 2005 et al.; Bender et al., 2010).

Windstorms are considered among the most important elements of the northeast forest disturbance regime, and forest health and ecological function depends on them in many ways 
(Dale et al., 2001; Oliver and Larson, 1996). On the other hand, an intensifying disturbance regime in forests that are already highly fragmented and stressed (i.e., less wind resistant) can increase the chance of damage to human habitation and utility infrastructure. The severe storms that struck the northeastern U.S. in 2011 and 2012 left widespread power outages across the region. It is estimated that up to $90 \%$ of power outages in tropical storm Irene (Aug. 2011) were the result of impacts of fallen branches or whole trees (McGee et al. 2012). As a result, and in accordance with recommendations in a review of the storm damage (McGee et al., 2012), utility companies have substantially increased their roadside vegetation management (i.e., tree trimming and removal) efforts across the northeastern U.S. (see United, 2013). For example, Eversource Energy, the largest utility company in New England, has allocated $\$ 75$ million for road-side vegetation management in just CT for 2017. Also, an additional \$10 million is being spent by state and local governments (S. Redding, personal communication) in a proactive effort to further reduce the impact of tree damage on utility infrastructure during storm events.

\subsection{The Study of Tree-Wind Interaction}

Previous studies examining the effects of wind on trees have shown that trees react to wind across temporal and spatial scales and begin with an immediate kinetic reaction to the force of the wind, wherein a tree sways and dissipates the force through motion of its trunk, roots and aerial architecture (Milne, 1991; Peltola, 1996). These bending stresses lead to adaptive, developmental change in the tree's physiology and morphology (Jafee, 1980; Telewski, 1995; Wood, 1995). Sway, the immediate reaction, can be described as a sinusoidal signal, having both a frequency (revolutions-per-second of trunk $(\mathrm{Hz})$, also known as a trees' fundamental vibrational frequency $(\mathrm{FVF})$ ) and an amplitude (the distance that a trunk moves during a sway from its resting position, i.e., its displacement). Sway is a function of the elastic qualities of 
woody material as well as the architectural (bole, roots and branches) and dynamic (streamlining tendencies and competing frequencies within crown) characteristics of the tree (Moore \& Maguire, 2004, Rodrigues et al., 2012). Motion damping, the dissipation of energy leading to the eventual cessation of sway, is a function of aerodynamic drag, viscoelastic drag and friction with neighboring trees when applicable (Milne, 1991). Also, theorized to contribute to damping is the crown-and-bole structure of components oscillating at unique frequencies, but coupled together. The competing frequencies prevent the bole from achieving a resonant frequency with the wind, which would exponentially amplify the amplitude and lead to overturning or trunk breakage (Sellier and Fourcaud, 2005; Theckes et al., 2011; Schindler et al., 2013).

The long-term reaction a tree has to wind is achieved over successive growing seasons as the tree adapts to a wind regime. A woody plant experiencing a great deal of physical perturbation from wind, allocates more resources to the development of wind-firm features. These can include a widened or buttressed base, increased root anchorage, a more tapered trunk, less height growth, flagging to reduce drag, and shorter internodes and branching (Telewski, 1995; Vogel, 1996; Cordero, 1999). The growth and developmental response of trees to mechanical stimuli is called thigmomorphogenesis (Jaffe, 1973), and is the primary process by which trees become resistant to wind damage (Jaffe \& Forbes, 1993; Telewski, 2006). Thigmomorphogenesis has been demonstrated in numerous studies investigating the development of branching structure, taper, allocation of carbon, variation in wood cells, chemical production and even flowering times in response to mechanical stimulation (Ashby et al., 1979; Holbrook \& Putz, 1989; Ostler et al., 1996; Chehab et al., 2009). Thus, physical stimuli lead to morphological response, which in turn alters sway dynamics. For example, Baker (1997) found a collection of lime trees to be divisible into three categories of FVF, directly correlating to three 
categories of tree shape; more slender trees were found to have a lower frequency than those with thicker, more tapered stems, and in a previous study, lower FVF trees had been shown in models to fail at lower wind speeds (Baker, 1995). Baker (1995) suggested the reason for this is that trees tend to react more strongly in wind with a frequency similar to their own, and lower frequency winds are the most turbulent, eliciting the greatest displacement reactions from trees. Sway motion is an indicator of a trees susceptibility to failure in a wind event, and FVF, a quantifier of sway, is the focus of this study.

\subsubsection{Drivers of Fundamental Vibrational Frequency}

The vast majority of studies on the effects of wind on trees have been conducted with even-aged, monospecific coniferous plantations (see Milne, 1991; Gardiner, 1995; Gardiner et al., 1997; Moore, 2000; Moore \& Maguire, 2004 \& 2005; Jonsson et al. 2007). The preponderance of these studies induced tree sway by mechanical means (winching and releasing the tree trunks), for example in Norway spruce (Jonsson et al. 2007), Sitka spruce (Milne, 1991) and Monterey pine (Moore, 2000). Far fewer studies have been conducted on temperate deciduous tree species, and by and large have also used mechanically-induced treatments to simulate the effect of wind on trees (see Kane et al. 2014, for example with Acer saccharum; Roodbaraky et al., 1994 with Platanus).

Moreover, comparatively few studies have examined the effect of wind on tree FVF under differing environmental conditions, such as above versus below freezing temperatures and between periods when leaves are present or not. In one study that examined the effects of freezing on FVF, the authors found that FVF was higher in below-freezing temperatures than in above-freezing conditions (Granucci et al. 2013). Similarly, the influence of foliage on FVF has been investigated in only a few studies and involved either manual removal of branches or 
needles in coniferous trees (Milne, 1991, Moore and Maguire, 2005; Sellier and Fourcaud, 2005), or the study of a single broad leaf tree (Roodbarkay, 1994; Schindler at al., 2013) or broad-leaf species (Baker 1997). Among these studies, the removal of foliage has been consistently found to increase FVF.

Tree architecture has been examined often in studies of coniferous species, and generally slenderness has been found to predict FVF (Moore and Maguire, 2004), where slenderness is defined as diameter at breast height $(\mathrm{DBH})$ divided by tree height squared $\left(\mathrm{H}^{2}\right)$. In contrast, in open-grown sugar maples, one of the few studies of broad-leafed, deciduous species, cumulative branch diameter (and not $\mathrm{DBH} \cdot \mathrm{H}^{-2}$ ) was found to be the best predictor of FVF (Kane et al., 2014).

Studies predicting windthrow, while still most often developed for coniferous plantations, have also investigated deciduous species, mixes of species and real dynamic wind forces (Poulos and Camp, 2010; Nolet et al., 2012; Ciftci et al., 2014). Because sway is an important indicator of resistance to wind-throw, predictive factors found in these studies are also likely related to FVF. Nolet et al. (2012), in testing a novel method of measuring wind intensity in a northern hardwood forest, found susceptibility to wind-throw to be partially dependent on tree species and a species-DBH interaction, suggesting the vulnerability-DBH relationship varies with species. Poulos and Camp (2010) found tall slender trees with larger proportions of their height being live crown were the most likely to fail. In contrast, Ciftci (2014), in calculating failure probabilities for open grown trees, found that trees with greater crown volume to be more stable, owing to the damping effect of more branches. Wind-throw is also related to both the constant wind speed and wind turbulence (England et al., 2000), however, studies have not agreed that variation in wind influences FVF (Webb et al., 2013). Wind speed can cause varying levels of streamlining in a 
tree (Vogel, 1989), and that altering of architecture could lead to variation in FVF. However, FVF does not appear to be influenced by direction of the force on a tree (Jonsson et al., 2007; Kane et al. 2014).

In addition to the potential direct effects of wind on FVF, the shelter and the structure of the forest surrounding a tree may also influence sway motion, although this has not been widely studied, and the few studies to date show contrasting results. For instance, Gardiner et al. (1997) suggest that shelter and structure of the forest surrounding a non-edge tree would have little influence on the motion of a tree, because wind loading comes from above in closed-canopy conditions. In other studies, however, decreased contact with neighboring trees, owing to a forest thinning, was found both to increase FVF (Milne, 1991) as well as decrease it (Webb et al., 2013). While not directly studying FVF, Nolet et al. (2012) found that stand basal area had a significant and negative correlation to wind-throw susceptibility. Thus, it remains unknown what the potential impact of surrounding trees or stand structure may have on an individual tree's FVF.

Forest stands in much of the northeastern U.S. are naturally regenerated, un-managed, even-aged, stratified, temperate deciduous mixed stands (Butler et al., 2011). They form a mosaic of forest types and species mixes, being located in the overlap of ranges of northern and southern species (Kitteregde and Ashton, 1995; Wharton et al. 2004) Natural and human-driven disturbances and fragmentation contribute to the variety and complexity that characterize today's temperate deciduous forests across its northeastern U.S. range (Seymour \& White, 2002; Foster et al., 1998). The wind and motion dynamics of trees in this type and condition of forest are not well understood. However, understanding what factors govern tree sway in mixed temperate deciduous forest stands is essential for developing strategies to optimally manage forest land to 
maintain its ability to provide ecosystem services as well as mitigate the detrimental impact of woody vegetation on utility infrastructure during storms and high wind events.

In this study 41 trees were constantly measured in three closed-canopy, mixed-species, temperate deciduous forest stands over a one-year period. The objective of this study was to identify elements that were predictive of sway frequency (FVF) from characteristics of wind and temperature conditions, stand structure and tree architecture. To accomplish this objective, I formed five hypothesizes to be tested:

1) The presence or absence of foliage as well as above- versus below-freezing temperatures would contribute considerably to variation in FVF. During leafless periods and in below freezing conditions FVF would be higher than when trees had their canopy foliage present and were in above freezing temperatures.

2) Across these conditions, the intensity or turbulence of the wind would not be effective predictors of FVF, which would be in agreement with previous studies of coniferous stands.

3) In a closed canopy forest, surrounding trees effectively contribute to the aerial architecture of any one tree. Thus, an index describing the canopy density on the windward or on the leeward side of the tree (i.e., shelter or support by neighbors) would be a significant predictor of a tree's FVF.

4) Common measurements of stand structure (e.g., stems count or basal area) would be predictive of FVF, because of their impact on the formation of architecture and crown structure.

5) Stem slenderness $\left(\mathrm{DBH} \cdot \mathrm{H}^{-2}\right)$ has consistently been found to predict FVF in coniferous trees, which possess an excurrent architecture. However, the majority of trees in this study are deciduous species and have decurrent architectures. I expected that slenderness would not be a significant predictor of FVF, but that measures of crown size or shape would be. 


\subsection{Materials and Methodology}

\subsection{Study Sites}

Tree sway and weather conditions were monitored on three sites in Connecticut (Fig. 1). Sites were chosen to capture a diversity of wind conditions and representative forest types in temperate deciduous forests (Table 1) found in southern New England (Kittredge and Ashton, 1995; Butler et al., 2011). Sites were located along roads with power lines and each had an accompanying tower in a nearby open area established to continuously monitor wind and ambient temperature (see Instrumentation below).

The Storrs site was located in east central Connecticut in Storrs, CT in the University of Connecticut Forest. The site is midslope but has locally level topography (Fig. 2), is $183 \mathrm{~m}$ above sea level (a.s.1.) and is typical of a southern New England temperate deciduous forests (see Dreiss and Volin, 2013). The Torrington site was located in northwestern Connecticut. The site has the highest elevation among the three at 366m a.s.l. (Fig. 3). The forest floor is noted for a large number of boulders and seasonal rivulets. The Orange site was located in south central Connecticut in the Town of Orange. The site has the lowest elevation among the three at $61 \mathrm{~m}$ a.s.1. It has a level topography (Fig. 4) and is flood prone.

\subsection{Instrumentation}

Across the three sites 41 trees $(13,14$, and 14 at Storrs, Torrington, and Orange, respectively) (Table 2) were continuously monitored with biaxial clinometers (A-900 model; Applied Geomatics, now Jewell Instruments, Manchester, NH) to determine the tilt of each tree in four directions. The A-900 biaxial clinometers have a range of $+/-10^{\circ}$ and a resolution of $0.01^{\circ}$ arc, and have been shown to be robust for this type of field measurement (Rudnicki et 
Figure 1: Location of Study Sites

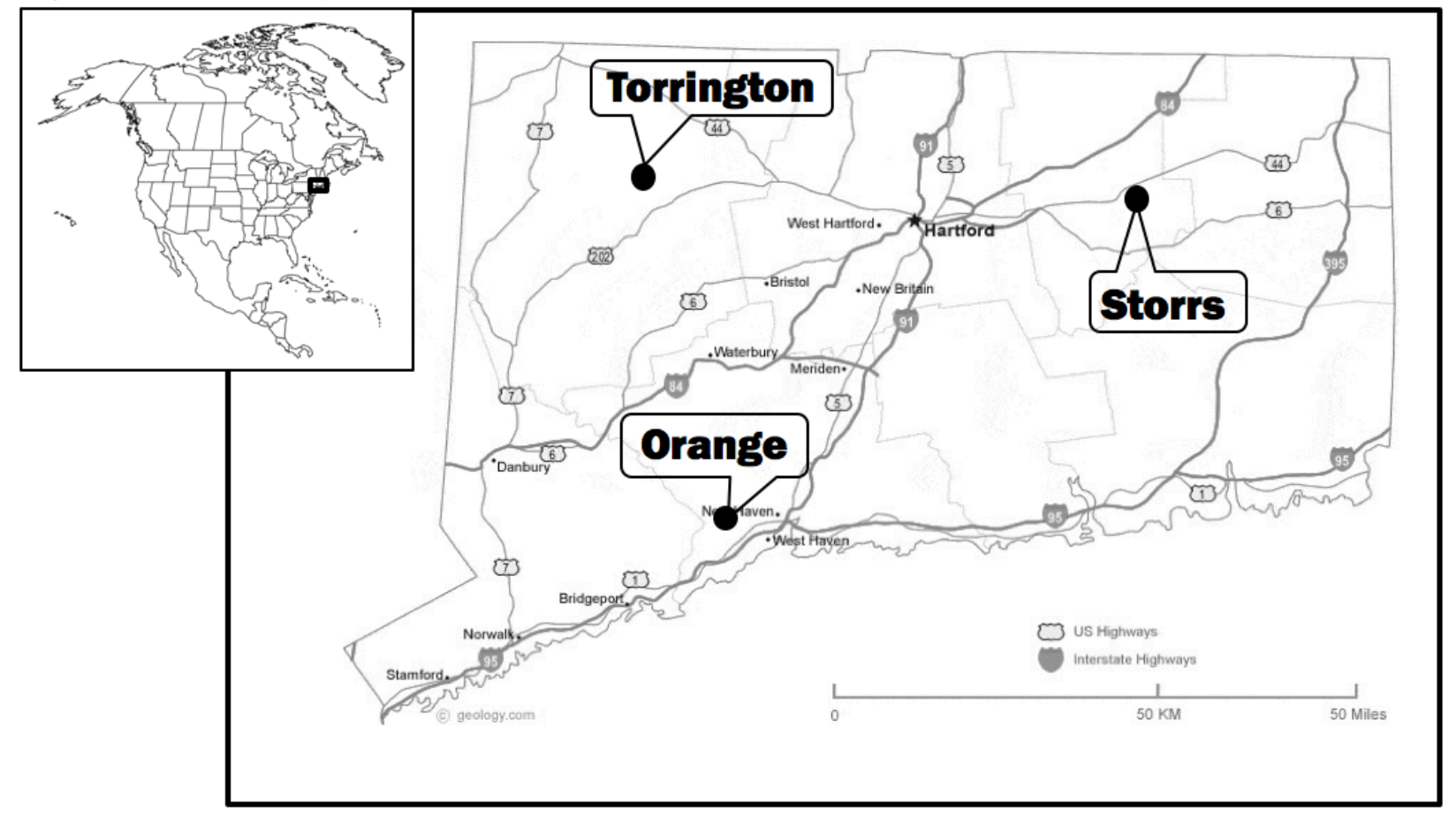


Table 1: Descriptions of three study sites

\begin{tabular}{|c|c|c|c|}
\hline Site township > & Storrs, CT & Torrington, CT & Orange, $\mathrm{CT}$ \\
\hline Location & $41.8084^{\circ} \mathrm{N}, 72.2495^{\circ} \mathrm{W}$ & $41.8003^{\circ} \mathrm{N}, 73.1212^{\circ} \mathrm{W}$ & $41.2786^{\circ} \mathrm{N}, 73.0265^{\circ} \mathrm{W}$ \\
\hline Date established & September, 2012 & August, 2014 & January, 2015 \\
\hline Date thinned & August, 2013 & June, 2016 & February, 2016 \\
\hline \multirow[t]{2}{*}{ Plot size } & $30 \mathrm{~m} \times 60 \mathrm{~m}$ & $30 \mathrm{~m} \times 100 \mathrm{~m}$ & $30 \mathrm{~m} \times 160 \mathrm{~m}$ \\
\hline & 0.4448 ac, 0.18 ha & $0.741 \mathrm{ac}, 0.48 \mathrm{ha}$ & $1.177 \mathrm{ac}, 0.74 \mathrm{ha}$ \\
\hline Elevation & $510 \mathrm{ft} ., 183 \mathrm{~m}$ ASL & $1020 \mathrm{ft} ., 366 \mathrm{~m}$ ASL & $200 \mathrm{ft} ., 61 \mathrm{~m} \mathrm{ASL}$ \\
\hline \multirow[t]{3}{*}{ Soil Type } & $\begin{array}{l}\text { Woodbridge fine sandy } \\
\text { loam }\end{array}$ & Ridgebury, Leicester and & Ninigret and tisbury soils \\
\hline & $3-15 \%$ slope & Whitman soils & $0-5 \%$ slopes \\
\hline & very stony & $\begin{array}{l}\text { Woodbridge fine sandy loam } \\
2-15 \% \text { slopes } \\
\text { extremely stony }\end{array}$ & \\
\hline \multirow[t]{6}{*}{ Species distribution } & Betula lenta $(34 \%)$ & Acer rubrum (46\%) & Acer rubrum (57\%) \\
\hline & Carya glabra and & Fraxinus americana (19\%) & Quercus rubra and \\
\hline & C. ovata $(26 \%)$ & Acer saccharum $(18 \%)$ & Q. velutina $(18 \%)$ \\
\hline & Acer saccharum and & Pinus strobus (4\%) & Nyssa sylvatica $(14 \%)$ \\
\hline & A. rubrum $(23 \%)$ & Tsuga canadensis (4\%) & Carya glabra, C. ovata, \\
\hline & $\begin{array}{l}\text { Quercus velutina }(13 \%) \\
\text { Fraxinus americana and } \\
\text { mix understory species (4\%) }\end{array}$ & $\begin{array}{l}\text { mix understory species and } \\
\text { pioneer species }(9 \%)\end{array}$ & $\begin{array}{l}\text { Liriodendron tulipifera, } \\
\text { and mix understory }(11 \%)\end{array}$ \\
\hline \multirow[t]{5}{*}{ Size distribution } & $10-20 \mathrm{~cm} \mathrm{DBH}(50 \%)$ & $10-20 \mathrm{~cm}$ DBH (68\%) & $10-20 \mathrm{~cm}$ DBH (31\%) \\
\hline & 20-30 cm DBH (18\%) & 20-30 cm DBH (23\%) & 20-30 cm DBH (20\%) \\
\hline & 30-40 cm DBH (11\%) & 30+ cm DBH (10\%) & 30-40 cm DBH (20\%) \\
\hline & $40-50 \mathrm{~cm} \mathrm{DBH} \mathrm{(10 \% )}$ & & $40-50 \mathrm{~cm} \mathrm{DBH} \mathrm{(20 \% )}$ \\
\hline & $50+\mathrm{cm}$ DBH (11\%) & & $50+\mathrm{cm}$ DBH (9\%) \\
\hline \multirow[t]{2}{*}{ Basal Area (pre-thin) } & $176.1 \mathrm{ft}^{2} / \mathrm{acre}$ & $168.3 \mathrm{ft}^{2} /$ acre & $168.1 \mathrm{ft}^{2} /$ acre \\
\hline & $40.4 \mathrm{~m}^{2} / \mathrm{Ha}$ & $38.6 \mathrm{~m}^{2} / \mathrm{Ha}$ & 38.6 m²/Ha \\
\hline \multirow[t]{2}{*}{ Stem Density (pre-thin) } & 204 stems/acre & 467 stems/acre & 175 stems/acre \\
\hline & 504 stems/Ha & 1153 stems/Ha & 432 stems/Ha \\
\hline \multicolumn{4}{|c|}{ Elevations: USGS National Topographic Maps } \\
\hline \multicolumn{4}{|c|}{ Soils types: USDA SSURGO NRCS Soil Survey } \\
\hline
\end{tabular}


Figure 2: Topography map of the area surrounding the Storrs, CT site

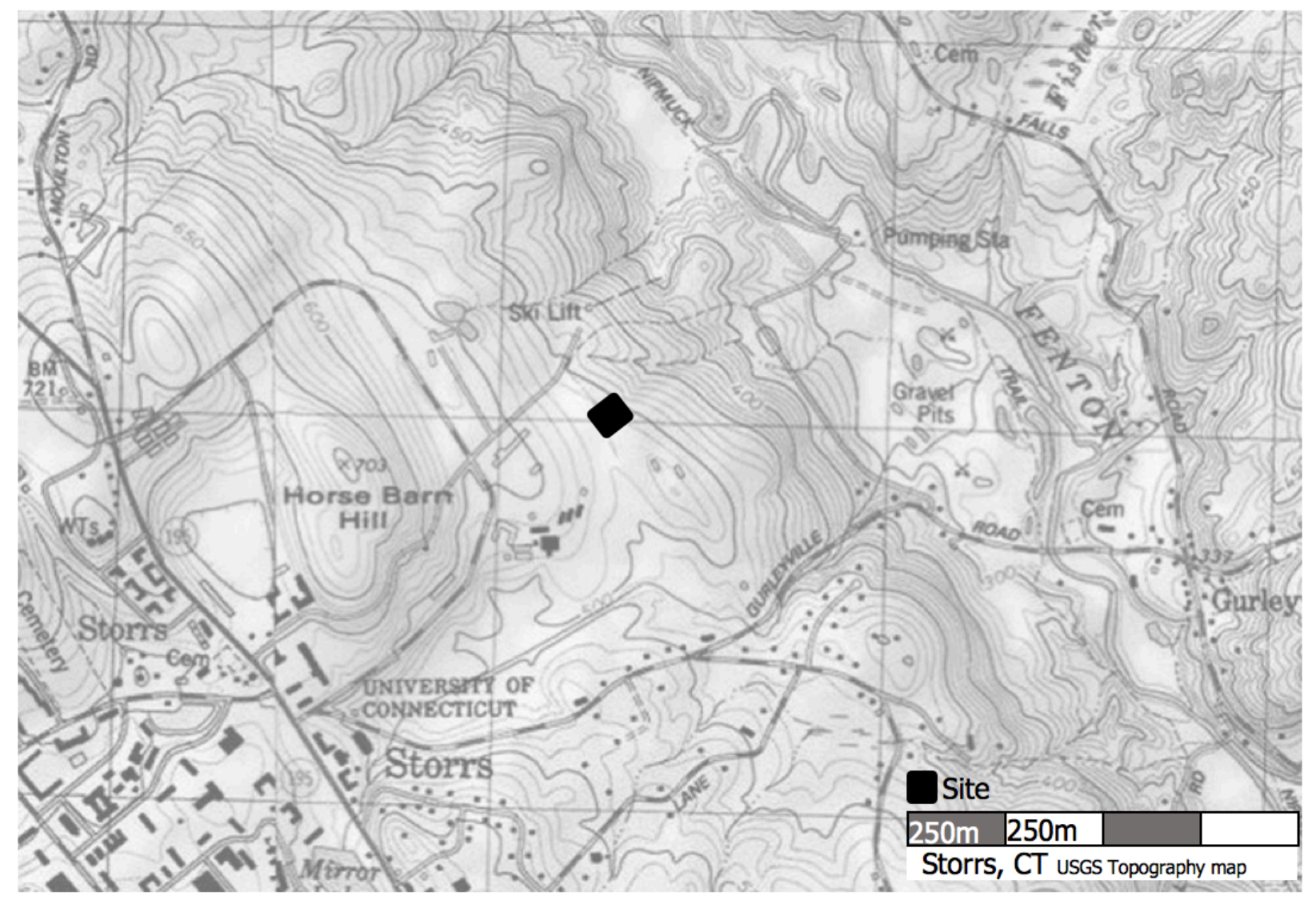


Figure 3: Topography map of the area surrounding the Torrington, CT site

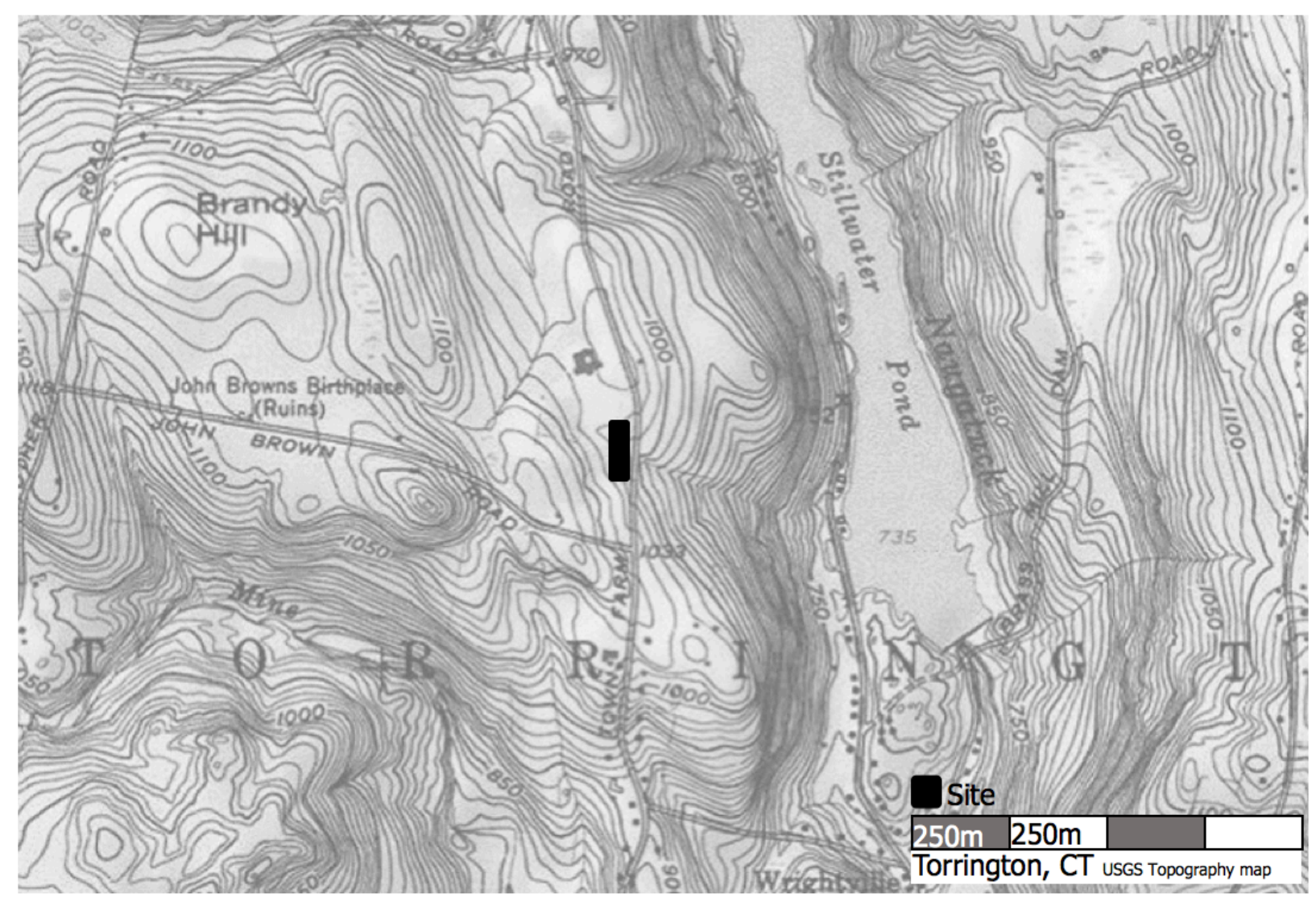


Figure 4: Topography map of the area surrounding the Orange, CT site

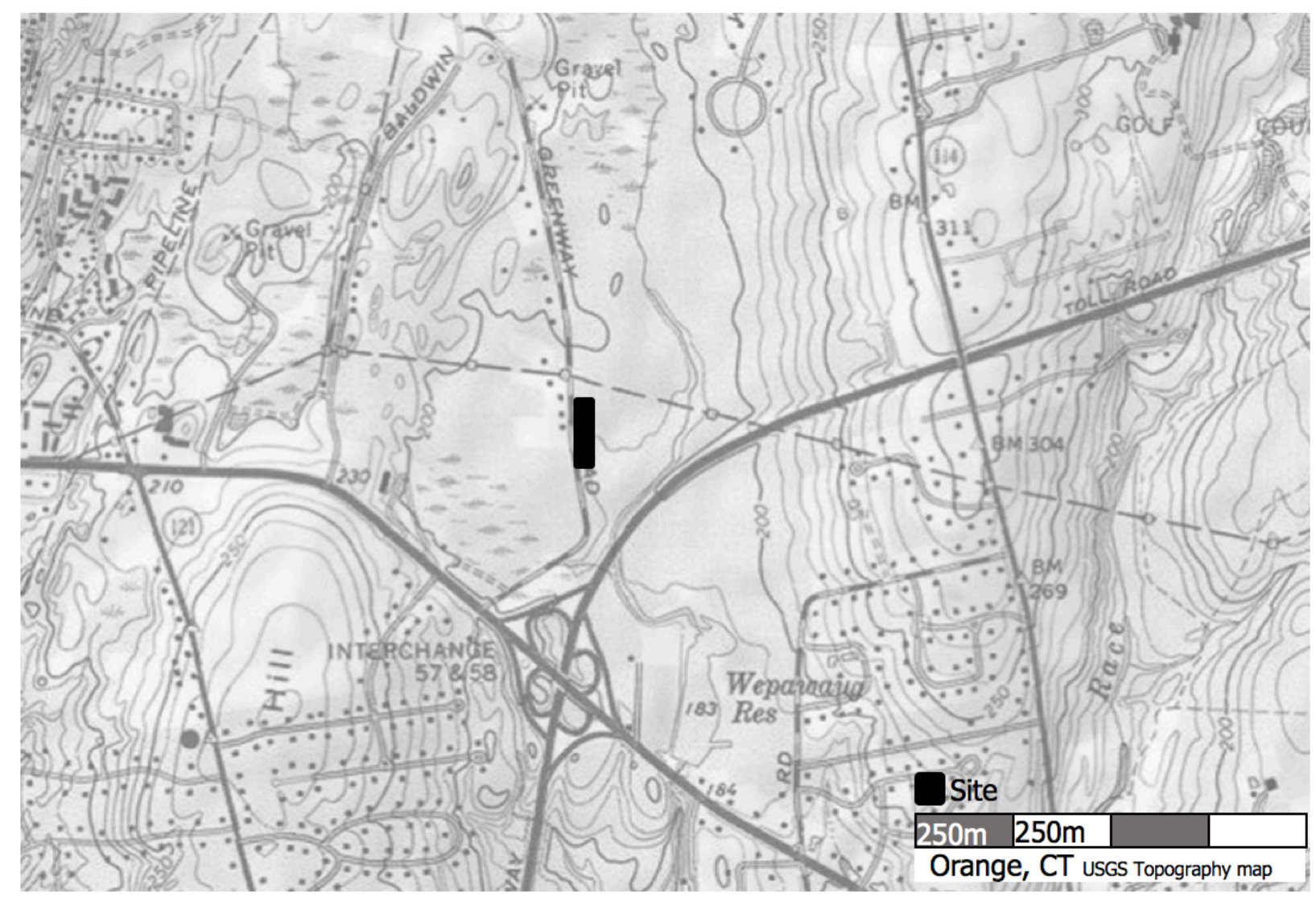


Table 2: Descriptions of the forty-one study trees

\begin{tabular}{|c|c|c|c|c|c|c|c|}
\hline $\begin{array}{l}\text { Tree } \\
\text { Tag \# }\end{array}$ & Site & Species & DBH (cm) & HT (m) & $\begin{array}{l}\text { Avg. Crown } \\
\text { Radius (m) }\end{array}$ & $\begin{array}{l}\text { Relative } \\
\text { Height }\end{array}$ & Position \\
\hline 2836 & Orange & Acer rubrum & 17 & 18.5 & 2.025 & overtop & interior \\
\hline 2841 & Orange & Nyssa Sylvatica & 15 & 11.23 & 1.8 & overtop & interior \\
\hline 2851 & Torrington & Acer rubrum & 25.3 & 16.8 & 1.555 & intermediate & interior \\
\hline 2852 & Torrington & Acer rubrum & 34.1 & 21.3 & 3.5775 & co-dominant & interior \\
\hline 2853 & Torrington & Acer rubrum & 16.1 & 15.2 & 2.4 & overtop & interior \\
\hline 2880 & Torrington & Pinus strobus & 55.8 & 24 & 4.425 & dominant & interior \\
\hline 2906 & Torrington & Quercus rubra & 32.3 & 17.7 & 4.075 & co-dominant & interior \\
\hline 2918 & Torrington & Quercus rubra & 22.1 & 17.4 & 2.4 & co-dominant & interior \\
\hline 2939 & Torrington & Acer saccharum & 14.6 & 15.2 & 1.775 & overtop & edge \\
\hline 3042 & Torrington & Quercus rubra & 23.7 & 17.5 & 2.3 & dominant & edge \\
\hline 3087 & Torrington & Acer saccharum & 14.9 & 15.8 & 1.775 & intermediate & interior \\
\hline 3132 & Orange & Carya ovata & 34.5 & 23.08 & 3.35 & co-dominant & edge \\
\hline 3156 & Orange & Nyssa Sylvatica & 32.5 & 20.1 & 2.4 & co-dominant & edge \\
\hline 3170 & Orange & Acer rubrum & 40 & 23.5 & 3.975 & co-dominant & interior \\
\hline 3176 & Orange & Carya glabra & 41 & 27.5 & 3.925 & dominant & interior \\
\hline 3178 & Orange & Liriodendron tulipifera & 22 & 13.72 & 2.925 & overtop & interior \\
\hline 3181 & Orange & Liriodendron tulipifera & 19 & 13.41 & 2.35 & overtop & interior \\
\hline 3306 & Orange & Quercus rubra & 49 & 27.9 & 4.725 & dominant & interior \\
\hline 3312 & Orange & Nyssa Sylvatica & 37 & 22.9 & 3.25 & co-dominant & interior \\
\hline 3328 & Orange & Acer rubrum & 39 & 22.86 & 5.15 & co-dominant & interior \\
\hline 3359 & Orange & Nyssa Sylvatica & 23.1 & 19.2 & 2.2 & overtop & interior \\
\hline 3399 & Orange & Carya glabra & 28 & 20.51 & 3.15 & co-dominant & interior \\
\hline 3400 & Orange & Liriodendron tulipifera & 45 & 24.5 & 3.3 & co-dominant & interior \\
\hline 3431 & Torrington & Acer rubrum & 27.5 & 19.6 & 2.9 & co-dominant & interior \\
\hline 3566 & Torrington & Acer saccharum & 18.75 & 8.2 & 2.8525 & intermediate & edge \\
\hline 3910 & Torrington & Acer saccharum & 11.8 & 14.6 & 1.625 & intermediate & interior \\
\hline 3920 & Torrington & Pinus strobus & 29.8 & 19.8 & 2.825 & dominant & interior \\
\hline 3944 & Torrington & Quercus rubra & 31.5 & 19.5 & 5.5 & co-dominant & edge \\
\hline 4133 & Storrs & Carya ovata & 30.3 & 21.68 & 6.0575 & co-dominant & interior \\
\hline 4187 & Storrs & Acer saccharum & 58.5 & 27.06 & 6.6675 & co-dominant & edge \\
\hline 4193 & Storrs & Acer saccharum & 18 & 16.68 & 3.6075 & overtop & interior \\
\hline 4201 & Storrs & Carya glabra & 44.2 & 27.75 & 5.5975 & co-dominant & interior \\
\hline 4210 & Storrs & Carya ovata & 46 & 29.79 & 2.7225 & co-dominant & edge \\
\hline 4218 & Storrs & Betula lenta & 34.7 & 31.35 & 6.8175 & co-dominant & interior \\
\hline 4230 & Storrs & Betula lenta & 11.8 & 13.92 & 2.28 & overtop & interior \\
\hline 4246 & Storrs & Carya ovata & 46.3 & 28.14 & 5.4675 & co-dominant & interior \\
\hline 4319 & Storrs & Carya glabra & 44 & 32.03 & 5.935 & dominant & edge \\
\hline 4390 & Storrs & Quercus rubra & 67.6 & 31.18 & 5.2675 & dominant & edge \\
\hline 4415 & Storrs & Carya ovata & 39.2 & 30.55 & 4.04 & dominant & edge \\
\hline 4444 & Storrs & Acer saccharum & 23.2 & 17.95 & 3.065 & overtop & interior \\
\hline 4669 & Storrs & Betula lenta & 42.2 & 27.3 & 5.915 & co-dominant & interior \\
\hline
\end{tabular}


al., 2001). In all, eight different deciduous (Acer rubrum, A. saccharum, Carya glabra, C. ovata, Betula lenta, Liriodendron tulipifera, Nyssa sylvatica, and Quercus rubra) and one coniferous (Pinus strobus) tree species were represented across a range of sizes: 12 to $68 \mathrm{~cm}(\mu=32 \mathrm{~cm})$ DBH and 8 to $32 \mathrm{~m}(\mu=21 \mathrm{~m})$ height. Chosen trees were canopy trees (dominant, co-dominant, intermediate or slightly overtopped), appeared healthy, and none were directly touching another monitored tree.

Each biaxial clinometer was anchored to the trunk at about $10 \mathrm{~m}$ high or beneath any major forking, either screwed into the trunk, or strapped with steel bands and springs. Both methods allow for tree diameter growth. A signal wire was run from each clinometer to a data logger (Campbell Science, CR3000). The clinometers continuously track the tilt of the tree at $10 \mathrm{~Hz}$ (i.e., 10 measurements per second) (sensu Rudnicki et al., 2008).

A meteorological tower was established at each site in an adjacent clearing simultaneously recording wind speed and direction using 3-cup-and-vane (R.M. Young Wind Sentry, Campbell Science - 03002) or propeller vane (R.M. Young Wind Monitor, Campbell Science - 05103) anemometers located at $30 \mathrm{~m}$ above ground, approximately canopy height. An ambient temperature sensor was positioned at $2 \mathrm{~m}$ high. Meteorological data were measured and recorded at $1 \mathrm{~Hz}$ (Campbell Science, CR1000).

\subsection{Variables}

A wide array of variables were measured over the course of the study to characterize environmental conditions, forest stand conditions, and to describe individual tree architecture (Table 3). 
Table 3: Variables used in analysis. Stat refers to a description of the variable as it applies to the statistical model.

\begin{tabular}{|c|c|c|}
\hline Variable: & Stat & Calculation \\
\hline TAG & Categorical - 41 level & $\begin{array}{l}\text { Identifying number of a subject tree. This is applied as a random } \\
\text { effect in the mixed effect model. }\end{array}$ \\
\hline FVF & continuous & $\begin{array}{l}\text { Sway frequency over ten-minute period. This is the response } \\
\text { variable. }\end{array}$ \\
\hline INT & - & Intercept term in the mixed effect model \\
\hline Foliage & Categorical - 2 level & $\begin{array}{l}\text { leaves on or off, as determined by the time period for which } \\
\text { deciduous trees in CT were with or without foliage }\end{array}$ \\
\hline Freezing & Categorical - 2 level & Above and below freezing temperature $\left(\geq 5^{\circ} \mathrm{C} ; \leq-5^{\circ} \mathrm{C}\right)$ \\
\hline FF & Categorical - 3 level & $\begin{array}{l}\text { foliage/freezing condition (leaves on, above freezing; leaves off, } \\
\text { above freezing; leaves off, below freezing) }\end{array}$ \\
\hline MAXWSPD & Continuous & maximum wind speed in ten-minute period $\left(\mathrm{m} \cdot \mathrm{s}^{-1}\right)$ \\
\hline MEDWSPD & Continuous & median wind speed over ten-minute period $\left(\mathrm{m} \cdot \mathrm{s}^{-1}\right)$ \\
\hline TOD & Categorical - 3 level & time of day (sunrise-to-noon; noon-to-sunset; sunset-to-sunrise) \\
\hline SDWSPD & Continuous & standard deviation of wind speed from mean \\
\hline MXOAV & Continuous & maximum wind speed divided by mean wind speed \\
\hline SHEL & Continuous & $\begin{array}{l}\text { index of shelter from incoming wind } \\
\text { (function of surrounding forest and wind direction) }\end{array}$ \\
\hline SUPP & Continuous & $\begin{array}{l}\text { index of support by neighbors stifling tree sway } \\
\text { (function of surrounding forest and wind direction) }\end{array}$ \\
\hline BA & Continuous & basal area in $\mathrm{m}^{2}$, unique to a site \\
\hline STEM & Continuous & number of stems per hectare, unique to a site \\
\hline SITE & Categorical - 3 level & experimental site (Storrs, Torrington, Orange) \\
\hline $\mathrm{H}$ & Continuous & height of subject tree $(\mathrm{m})$ \\
\hline $\mathrm{DBH}$ & Continuous & diameter at breast height of subject tree $(\mathrm{cm})$ \\
\hline $\mathrm{DBH} \cdot \mathrm{H}^{-2}$ & Continuous & slenderness calculation 1: $\mathrm{DBH} \cdot \mathrm{H}^{-2}$ \\
\hline $\mathrm{DBH} \cdot \mathrm{H}$ & Interaction & slenderness calculation $2: \mathrm{DBH} \cdot \mathrm{H}$ \\
\hline$\Delta \mathrm{D}$ & Continuous & $\begin{array}{l}\text { slenderness 3: change in diameter per meter of trunk height } \\
\text { between DBH measurement and sensor height }\end{array}$ \\
\hline $\mathrm{E}$ & Continuous & $\begin{array}{l}\text { Young's modulus of elasticity (MPa) } \\
\text { specific to a species (Green et al., 2009) }\end{array}$ \\
\hline SPEC & Categorical - 9 level & species of subject tree \\
\hline DBH*SPEC & Interaction & species variable $* \mathrm{DBH}$ variable \\
\hline CANT & Continuous & $\begin{array}{l}\text { A parameter characterizing subject tree, } \\
\text { based on cantilever function (see AASHTO 2013) } \\
\text { (function of DBH, } \triangle \mathrm{DBH}, \mathrm{H} \text { and } \mathrm{E} \text { ) }\end{array}$ \\
\hline GRTOCR & Continuous & height from ground to base of live crown (m) \\
\hline CRTOTOP & Continuous & height from base of live crown to top of tree (m) \\
\hline CRHTPER & Continuous & percent of total tree height that is live crown \\
\hline CRRAD & Continuous & average radius of crown $(\mathrm{m})$ \\
\hline CRVOL & Continuous & $\begin{array}{l}\text { volume of crown }\left(\mathrm{m}^{2}\right) \text { (area of crown estimated from } \\
\text { radius measurements } \cdot \text { CRTOTOP) }\end{array}$ \\
\hline CRCLO & Continuous & crown closure: a measure of crown density from none to $100 \%$ \\
\hline SYMM & Continuous & $\begin{array}{l}\text { index of crown symmetry about trunk } \\
\text { (function of } 4 \text { radial measurements, N, S, E and W) }\end{array}$ \\
\hline
\end{tabular}




\subsubsection{Dependent Variables}

Sway Frequency, or Fundamental Vibrational Frequency (FVF), a measure of oscillations per second, expressed as hertz $(\mathrm{Hz})$, was taken for every 10 minutes of sway on each measured tree. It was calculated using the $10 \mathrm{~Hz}$ clinometer position data, averaged over every 1 second. Using the python (version 2.7) module "numpy" and its fft.rfft function, the discrete Fourier Transform of the sway dataset was computed using the Fast Fourier Transform algorithm. A series of coefficients for tested frequencies was produced, and a spectral diagram of frequencies was plotted using this procedure (Fig. 5). An algorithm was developed to smooth the power spectral diagram and identify the peak corresponding to the FVF (sensu Rudnicki et al., 2008).

The plot represents a series of peaks at any frequency of a moving tree part caught by the sensor, and FVF is the peak at the lowest frequency (because the bole is moving slower than any branches) and has the highest coefficient, corresponding to the strongest signal (because the instrument is physically on the bole, and not a branch, the movement signal of the bole is most pronounced).

\subsubsection{Predictor Variables}

Twenty-seven variables were examined to determine the best predictor for FVF (Table 3). Two environmental condition variables represented whether foliage was present or not (foliage), and whether the ambient temperature was below freezing or not (freezing). It should be noted that foliage condition (leaf-on or leaf-off) was determined by what season the record was taken in. Two study trees are not deciduous, and maintain their foliage all year, however, all trees together were included in the dataset. This was done because the intent of the model is to be generalized to the northeastern roadside forest and not specific to a tree. The criteria for freezing was that the air temperature was less than $-5^{\circ} \mathrm{C}$, and for above freezing, the air temperature was 
Figure 5: A spectral diagram describing the sway signal strength (FFT amplitude) at tested frequencies $(\mathrm{Hz})$. Included on the plot are the smoothed contour used to determine the FVF and the selected FVF.

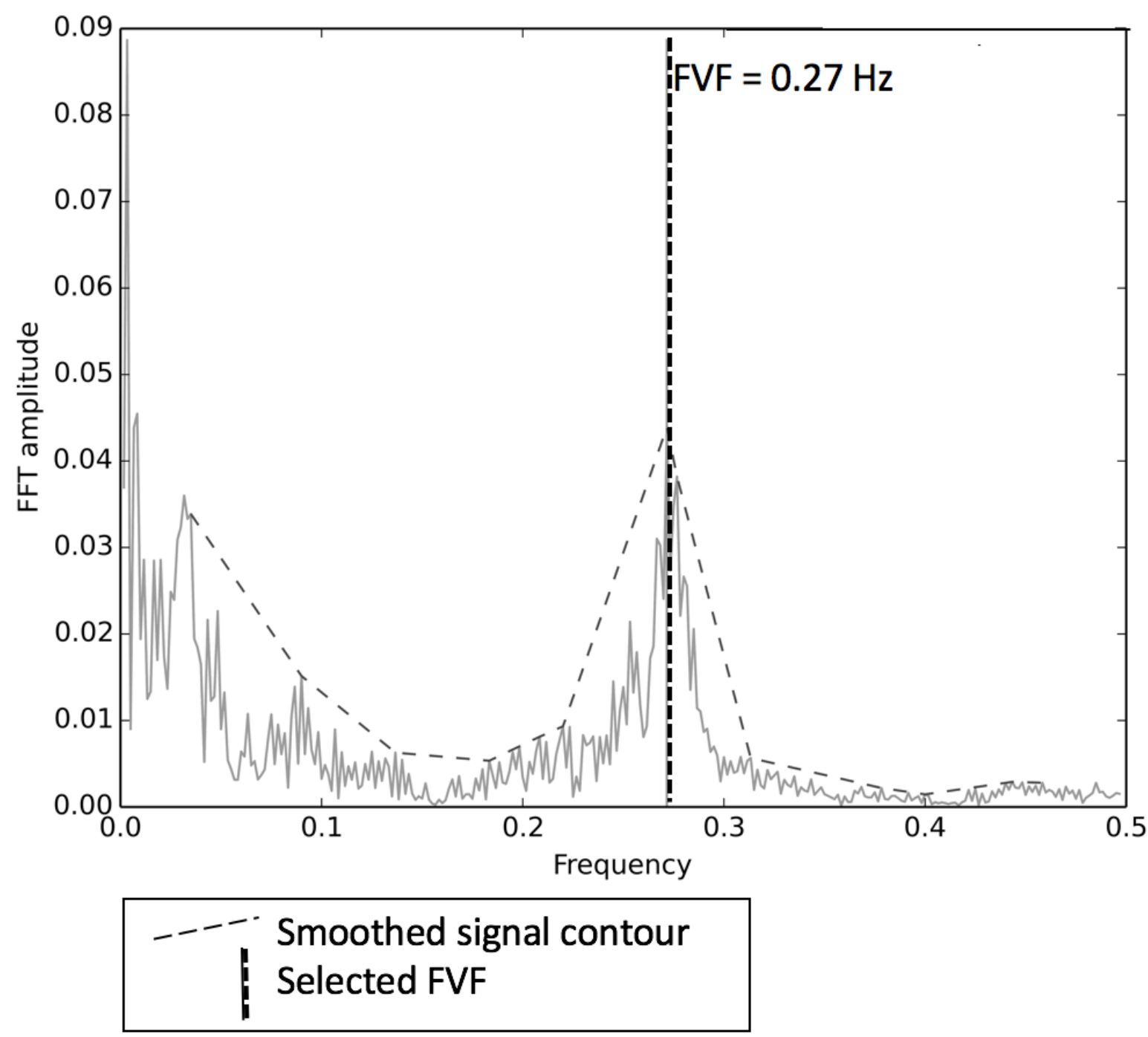


greater than $5^{\circ} \mathrm{C}$. It could not be determined exactly when the tree would achieve freezing temperatures, in comparison to the air, but a $5^{\circ} \mathrm{C}$ buffer has been deemed appropriate in a previous study (Granucci et al., 2013). The foliage and freezing variables were combined into a single three-level categorical variable, FF, for model development.

The wind condition was represented as the maximum wind speed in a ten-minute period (MAXWSPD) and the median (MEDWSPD). As wind speed and wind turbulence are known to change with time of day (Stull, 1988; Archer and Jacobson, 2005), time of day (TOD) was divided into three categories to represent the wind condition as well (these were: sunrise-to-noon, noon-to-sunset, and sunset-to-sunrise). Since it was not feasible to measure turbulence directly, two measures of fluctuation in wind velocity were used instead. They included the standard deviation of the wind speed in a 10-minute period (STWSPD) and the ratio of maximum to average wind speed in a ten-minute period (MAXOAV).

A derived shelter index was also tested. Here, shelter was defined as a measure of average canopy height, as compared to the height of a tree of interest, in the windward direction of that tree. The calculation was based on the wind direction as well as a LiDAR point cloud, which was used to create a height map of the canopy surface (canopy height map (CHM)) around the test tree (Fig. 6). To determine a suite of shelter indexes for a tree of interest, the canopy height map surrounding the tree is defined, from the edge of the tree's crown to $15 \mathrm{~m}$ out. Pixels of the canopy height map, within the defined area, are given a value relative to the height of the tree of interest (RCHM). Thus, a relative canopy height map is calculated as:

$$
\text { RCHM_value }=\text { CHM_value } / \text { height_of_tree of interest }
$$


Figure 6: Shelter and support indices were derived from a tree canopy height map where the pixels represent the ratio of the surrounding canopy height to the height of the tree of interest. The values were averaged and weighted (with the values in the ring closest to the tree of interest having the greatest weight) for the 90-degree wedge pertaining to the direction of the wind (for shelter) or opposite the direction of the wind (for support).
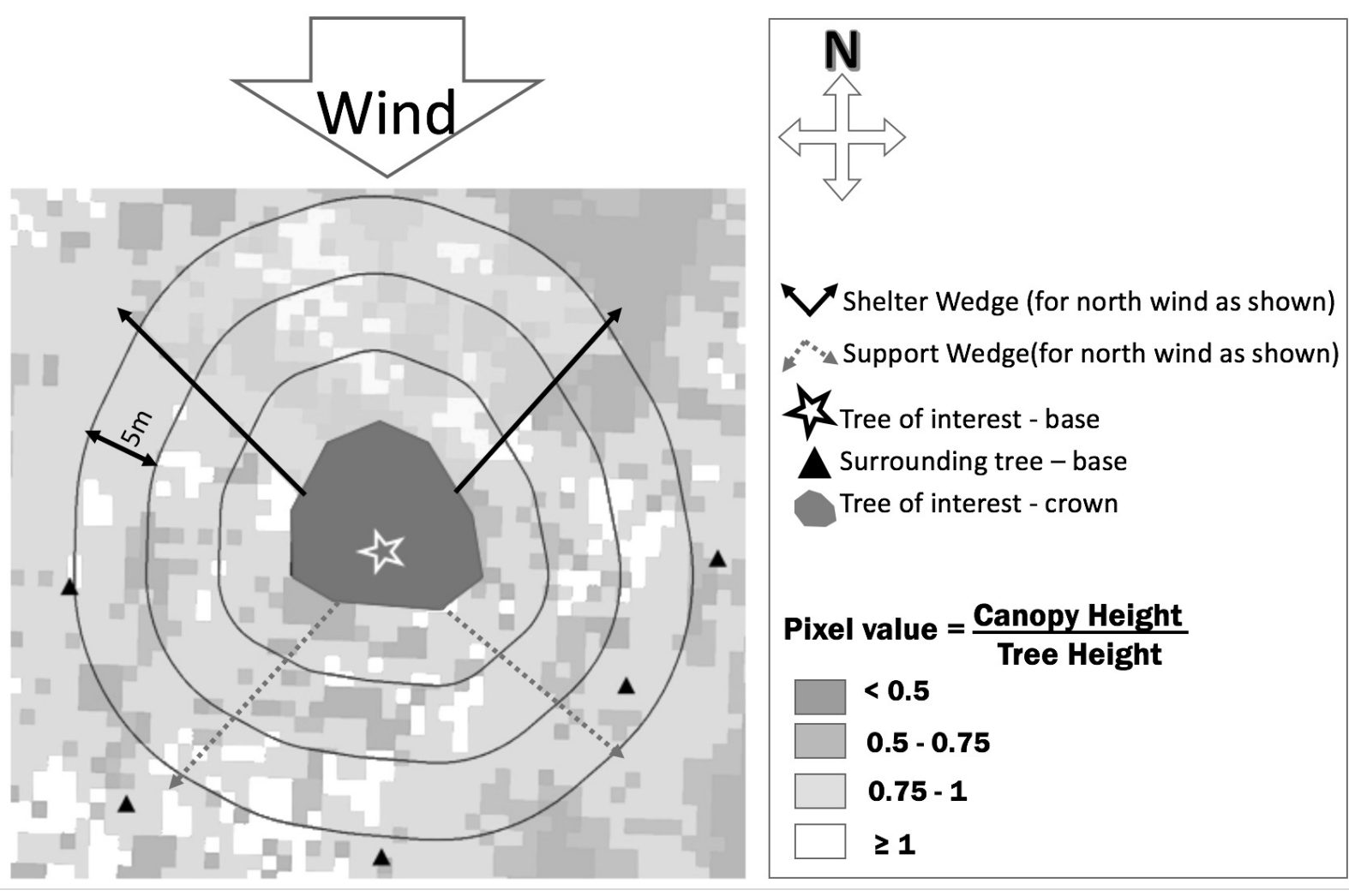
If the canopy height map value (CHM_value) of a pixel is less than the height of the base of the crown of the subject tree (measured manually) then the RCHM value becomes zero, since that pixel will not contribute to shelter.

Concentric rings with a width of $5 \mathrm{~m}(5 \mathrm{~m} \approx 1 / 4$ tree height for the trees in this dataset $)$ are demarked on the RCHM area around the tree of interest. Eight overlapping wedges of 90-degree sector angles, centered at due north, northeast, east, southeast, south, southwest, west and northwest are demarked around the tree of interest. The shelter index is the weighted average of the RCHM values found within the wedge, weighted according to which ring they fall in. For example:

Shelter_Index_WedgeN $=A v g(R C H M$, WedgeN, ring1 $) * 0.5+A v g(R C H M$, WedgeN, ring2 $) * 0.3$ $+\operatorname{Avg}(R C H M$, WedgeN, ring 3$) * 0.2$

Where $\mathrm{N}$ indicates a direction of North, in this example for a North wind.

In similar fashion, a measure of support, or support index, is calculated in the same manner except the value is that of the wedge corresponding to the downwind direction, and in this case, the direction in which it would be exerting force on the tree.

$$
\begin{gathered}
\text { Support_Index_WedgeS }=\operatorname{Avg}(\text { RCHM, WedgeS, ring1 }) * 0.5+\operatorname{Avg}(\text { RCHM, WedgeS, ring } 2) * 0.3 \\
+\operatorname{Avg}(R C H M, \text { WedgeS }, \text { ring } 3) * 0.2
\end{gathered}
$$

Where S indicates a direction of South, in this example for a North wind.

Tree height, diameter and slenderness were also determined. Tree height $(\mathrm{H})$ was measured using a laser rangefinder ("Impulse", Laser technologies Inc., Centennial, CO) and diameter at breast height (DBH) was measured with a DBH tape at a height of $1.4 \mathrm{~m}$. Tree slenderness was calculated using three different approaches: 1) $\mathrm{DBH} \cdot \mathrm{H}^{-2}$ (see Moore and Maguire, 2004), 2) $\mathrm{DBH} \cdot \mathrm{H}$ representing the collinear relationship of $\mathrm{DBH}$ to $\mathrm{H}$ (see Baker, 
1997; O'Brien et al., 1995), and 3) the change in diameter $(\Delta \mathrm{D})$ per meter between $\mathrm{DBH}$ and the trunk diameter at sensor height (i.e., $\approx 10 \mathrm{~m})$.

Additional predictor values included Young's modulus of elasticity (E), which is a measure of stiffness of an elastic material, where a greater value of E indicates bending to a lesser degree under a given load. In this case, it was measured from samples of clear green wood by Green (1999) and is species specific. Species was also used as a categorical variable representing the specific species of a tree, as well as the interaction of species and DBH (SPEC·DBH). The latter is a variable that has previously been found to be a significant predictor of FVF, where wind-throw susceptibility for a given size class of tree varied with species (Nolet et al., 2012).

A cantilever beam parameter (CANT) was also tested as a potential predictor of FVF. The CANT quantifies the properties of a tree when acted upon by a displacement force. It is a function of DBH, H, slenderness and E. Specifically, I used a variation of the cantilever beam equation commonly used to quantify the properties of a beam when acted upon by a displacement force (AASHTO, 2013), which is calculated as:

$$
\text { CANT }=\left(7.872(\mathrm{E})(\mathrm{I})\left(\mathrm{r}^{3.282}\right)\right) /(0.75(\mathrm{H}))^{4}
$$

Where $\mathrm{I}$ is the moment of inertia of a circular bole: $\mathrm{I}=\left(\pi \mathrm{r}^{2}\right) / 4$, and $\mathrm{r}$ is the ratio of two radii of a tapered bole calculated as: $\mathrm{r}=\left(\left(\mathrm{DBH}^{0.5}\right) / 100\right) /\left(\left(\mathrm{DSH}^{0.5}\right) / 100\right)$, where $\mathrm{DSH}$ is diameter at the height of the biaxial inclinometer.

Several measurements of the crown structure were also included as test parameters. Crown symmetry (SYMM) is the ratio of the crown width in the north/south direction to the crown width in the east/west direction. SYMM, which is equivalent to zero in the case of a perfectly symmetrical tree, is calculated as: 


$$
\text { SYMM }=(\text { North-radius }- \text { South-radius })+(\text { East-radius }- \text { West-radius })
$$

Further measures of crown structure included 1) the height from the ground to the base of the live crown (GRTOCR), 2) the height from the base of the crown to the top of the total height of the tree (CRTOTOP), 3) the percentage of the total height of the tree that was live crown (CRHTPER) (sensu Polous and Camp, 2010), 4) crown radius (CRRAD) calculated as the average of radial measurements in the four cardinal directions, 5) crown volume (CRVOL) calculated as an area derived from the four radial measurements, multiplied by CRTOTOP, and 6) crown closure (CRCLO) was also determined. Closure was derived from leaf-off LiDAR data using the hemispherical view-shed technique developed by Parent and Volin (2014). Canopy closure is highly correlated with leaf-area-index, a common measurement of canopy density (Chen et al., 1997). Canopy closure is also related to porosity (Macfarlane et al., 2007), a measurement common in shelterbelt studies (e.g., Bean et al., 1974; Zhu et al., 2002), but where closure is the density moving vertically through a canopy, porosity is the density in a horizontal direction.

\subsection{Statistical Analyses}

Prior to regression analysis, each variable was investigated for its correlation to FVF, either by pearson correlation coefficient (for continuous variables) or by analysis of variance (for categorical variables), using SAS statistical software (SAS 3.2, 2014).

Stepwise multiple regression of a linear mixed effects model was then used to determine the viability of each factor in predicting FVF. The stepwise procedure was used to iteratively test independent variables, and combinations thereof, using SAS's mixed model procedure (SAS 3.2, 2014). The mixed procedure assumes Gaussian distribution of the dependent variable and uses residual maximum likelihood to fit the data. Candidate models to test the variables were 
developed sequentially by first adding attributes of the weather, and proceeding to the surrounding forest conditions and finally attributes of the tree. No variables were included together if they were functions of one another, variant ways of quantifying the same predictor, or known to be highly correlated with one another.

The use of a p-value in the regression analyses was not appropriate for capturing the significance of a variable in the model because the large size of this dataset would cause p-values for variables to approach zero (see Lin et al., 2013). This causes overfitting of the model, or the creation of a model that is not general for the population, but specific to the sample dataset. Consequently, for the portion of this analysis where the data set exceeded 200,000 records (see Results 3.1-3.2), the effect of each variable on FVF was tested using 100 Monte Carlo simulations of the model, each fit with 1000 randomly selected records. We then looked at the range and average p-values that were produced for a variable. In cases where the dataset was reduced (see Results 3.3-3.4), candidate models were compared by their AIC values. Via this iterative process, the most appropriate predictors were determined for the final model. 


\subsection{Results}

\subsection{Environmental Variables}

\subsubsection{Foliage On/Off and Temperatures Above/Below Freezing}

Fundamental vibrational frequency (FVF) showed significant differences between leaf-on versus leaf-off conditions $(\mathrm{P}<0.0001)$ as well as in above freezing versus below freezing temperature conditions $(\mathrm{P}<0.0001)$ (Fig. 7) in the full dataset $(\mathrm{n}=218,499)$. For model development, these two variables were combined into a single categorical variable (FF) describing conditions as 1) leaf-on and above freezing, 2) leaf-off and above freezing, and 3) leaf-off and below freezing. The leaf-on and below freezing condition did not occur in this dataset. The condition of leaf-on and above freezing had the lowest FVF while the leaf-off and below freezing had the highest FVF (Fig.8).

The FF variables were significant $(\mathrm{P}<0.0001)$ in a model predicting FVF. The FF variables maintained significance $(\mathrm{P}<0.0001)$ when the model including FF was run as 100 Monte Carlo simulations of 1000 random data points (Table 4). Thus, FF was used in the following model to predict FVF, where INT represents an intercept term:

$$
\mathrm{FVF}=\mathrm{INT}+\beta(\mathrm{FF})
$$

\subsubsection{Wind Speed}

Three parameters representing wind speeds at time of the FVF record were tested. These were maximum wind speed (MAXWSPD), median wind speed (MEDWSPD) and time of day (TOD). The first two, MAXWSPD and MEDWSPD were both significantly, although weakly, correlated with FVF (r=0.15 and 0.13, respectively, at $(\mathrm{P}<0.0001)$ ) (Fig. 9). The third wind speed variable, a categorical variable specifying time of day of the FVF recording, displayed 
Figure 7: Distribution of fundamental vibrational frequency $(F V F)$ with foliage present (leafon_or absent (leaf-off) and above freezing $\left(>5^{\circ} \mathrm{C}\right)$ or below freezing $\left(<-5^{\circ} \mathrm{C}\right)$. Different letters denote significant $(p<0.0001)$ variation in mean FVF.

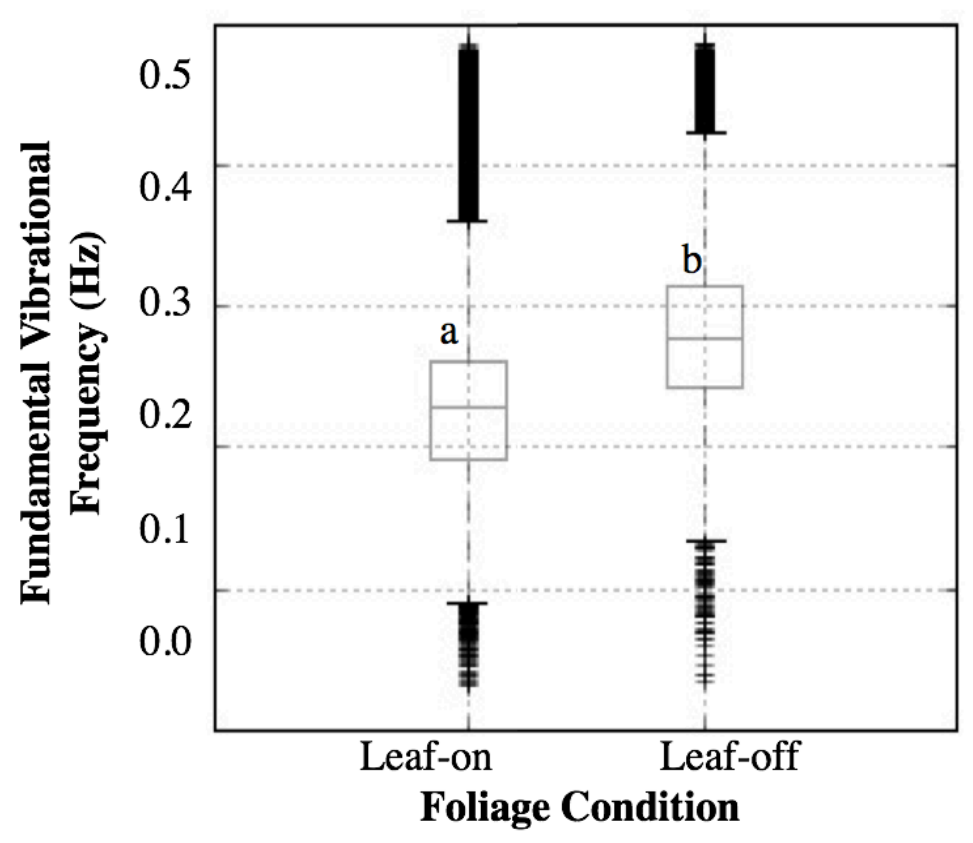

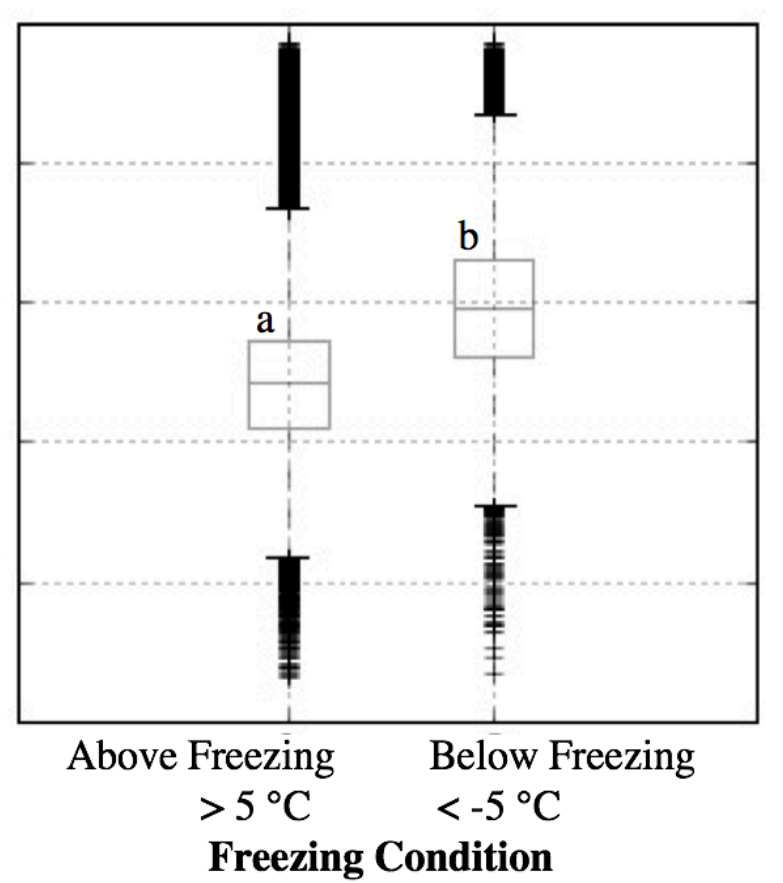


Figure 8: Distribution of fundamental vibrational frequency $(F V F)$ in the 3 conditions, (1) leafon-above-freezing, (2) leaf-off-above-freezing and (3) leaf-off-below-freezing. Different letters denote significant $(p<0.0001)$ variation in mean FVF.

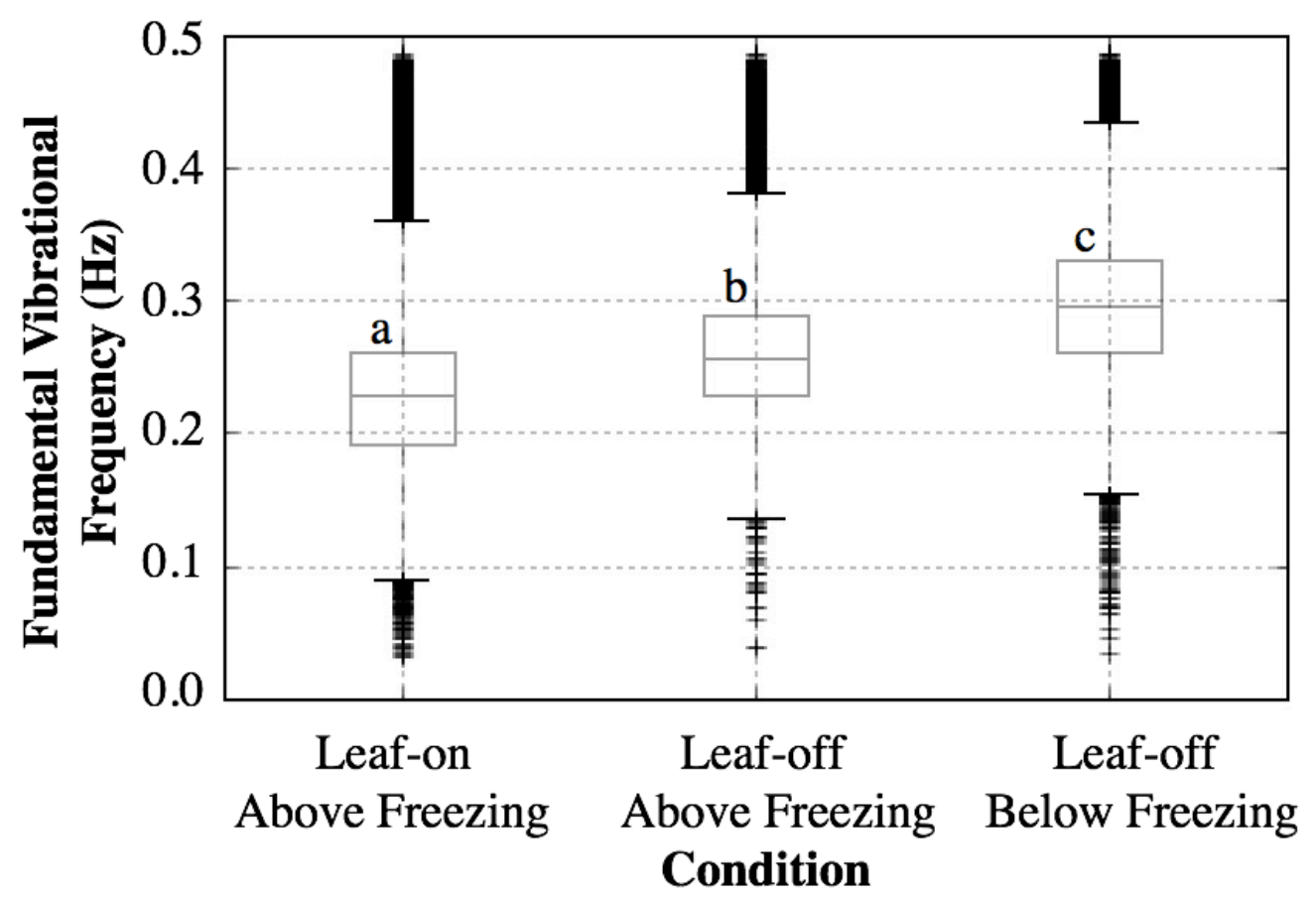


Table 4: 100 Monte Carlo iterations of the model $F V F=I N T+F F$, with 1000 randomly selected data points. See Table 3 for acronym definitions and variable descriptions.

\begin{tabular}{lllll}
\hline $\begin{array}{l}\text { Model: FVF }=\text { INT }+ \text { FF } \\
\text { Predictor }\end{array}$ & Coeff. Estimate range & Estimate mean & p-value range & p-value mean \\
\hline INT & 0.2945 to 0.3031 & 0.2984 & $<0.0001$ & $<0.0001$ \\
FF(1) & -0.0812 to -0.0667 & -0.0745 & $<0.0001$ & $<0.0001$ \\
FF(2) & -0.0392 to -0.0286 & -0.0348 & $<0.0001$ & $<0.0001$ \\
\hline
\end{tabular}


Figure 9: Fundamental Vibrational Frequency (FVF) plotted on both maximum wind speed and median wind speed, with a least-squares regression line indicating positive relationships in both data sets $(n=218,499)$.
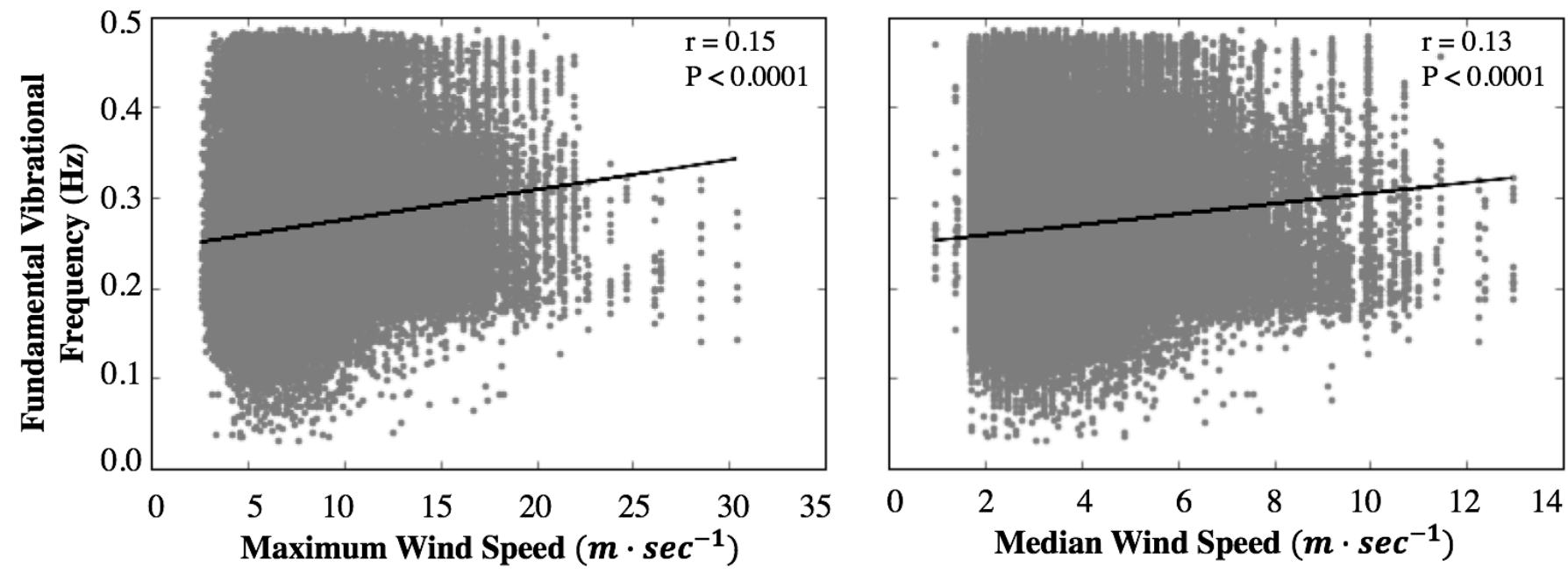
significant $(\mathrm{P}<0.0001)$ variation in FVF among its three categories, with FVF being significantly higher from sunset-to-sunrise, followed by sunrise-to-noon, and noon-to-sunset was lowest $(\mathrm{P}<0.0001)$ (Fig. 10).

Maximum wind speed was found to be significant $(\mathrm{P}<0.0001)$ in predicting FVF in a model with INT as the only other term (Table 5a). However, when FF was also included, the effect of MAXWSPD declined dramatically from having a regression coefficient of 0.00359 to 0.00042 (Table 5a). Monte Carlo simulations of the model showed the estimate for the coefficient of MAXWSPD ranging above and below 0.0 and its P-value became less significant, averaging $\mathrm{P}>0.05$ (Table 5b), where it had been significant $(\mathrm{P}<0.0001)$ before FF was added to the model. However, the estimates for the coefficients of the FF variables remained significant (P $<0.0001$ ) (Table 5b). A similar response was found when MEDWSPD was incorporated in the model (Table 5a and 5b). The effect of these variables was close to zero and their significance in the model was not supported.

Figure 11 represents the effect of MAXWSPD on FVF across all FF conditions plotted together, as well as separated by the three FF conditions. As mentioned above, when data were pooled, FVF was significantly, although weakly, correlated with MAXWSPD. However, the significant correlation disappears when the data are broken out by the three conditions. T-tests showed that there were significant differences in the MAXWSPD under the three conditions $(\mathrm{P}<0.0001)$ (Fig. 12), lending support to the fact that MAXWSPD was not effective in the model. Similar responses were also found for MEDWPSD (data not shown).

Time of day was also used as a wind speed variable because wind speeds tend to be correlated with the time of day (Archer and Jacobson, 2005). Contrary to expectations, (see 
Figure 10: Distributions of fundamental vibrational frequency $(F V F)$ as grouped by time of day with different letters denote significant difference of means.

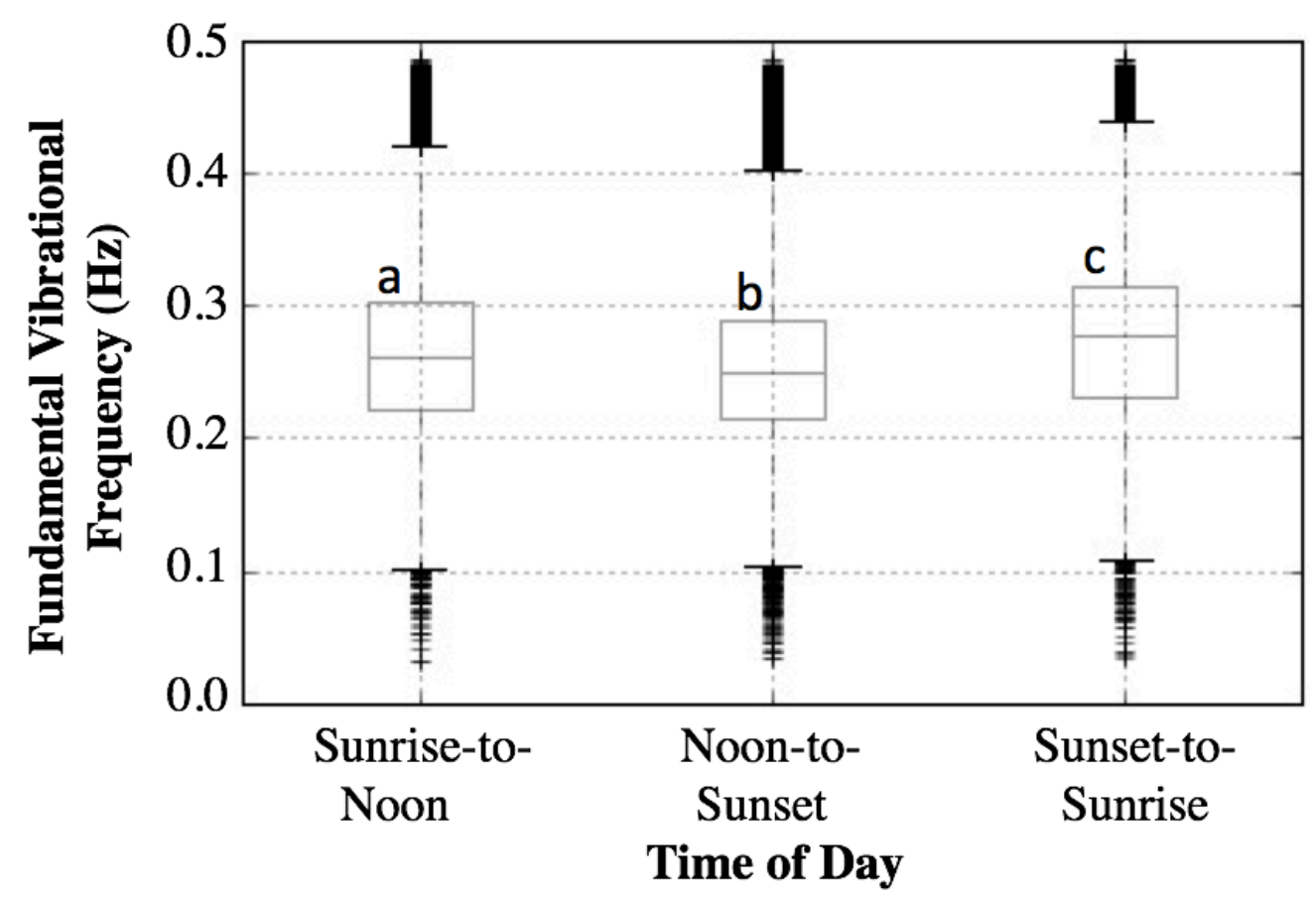


Table 5a: The variable coefficients as estimated for each indicated model, when the model was fit with the entire dataset, are listed herein. See Table 3 for acronym definitions and variable descriptions.

\begin{tabular}{llll}
\hline Model: FVF $=$ INT + MAXWSPD & Variable & Coeff. estimate & P-val \\
\cline { 2 - 4 } & INT & 0.23830 & $<0.0001$ \\
& MAXWSPD & 0.00358 & $<0.0001$ \\
\hline Model: FVF $=$ INT + FF +MAXWSPD & Variable & Coeff. estimate & P-val \\
\cline { 2 - 4 } & INT & 0.30210 & $<0.0001$ \\
& FF(1) & -0.07545 & $<0.0001$ \\
& FF(2) & -0.03519 & $<0.0001$ \\
& MAXWSPD & -0.00042 & $<0.0001$ \\
\hline Model: FVF $=$ INT + MEDWSPD & Variable & Coeff. estimate & P-val \\
\cline { 2 - 4 } & INT & 0.23580 & $<0.0001$ \\
& MEDWSPD & 0.00833 & $<0.0001$ \\
\hline Model: FVF $=$ INT + FF +MEDWSPD & Variable & Coeff. estimate & P-val \\
\cline { 2 - 4 } & INT & 0.30220 & $<0.0001$ \\
& FF(1) & -0.07566 & $<0.0001$ \\
& FF(2) & -0.03524 & $<0.0001$ \\
& MEDWSPD & -0.00088 & $<0.0001$ \\
\hline Model: FVF $=$ INT + TOD & Variable & Coeff. estimate & P-val \\
\cline { 2 - 4 } & INT & 0.27820 & $<0.0001$ \\
& TOD $(1)$ & -0.01559 & $<0.0001$ \\
& TOD $(2)$ & -0.24080 & $<0.0001$ \\
\hline Model: FVF $=$ INT + FF + TOD & Variable & Coeff. estimate & P-val \\
\cline { 2 - 4 } & INT & 0.29880 & $<0.0001$ \\
& FF(1) & -0.07399 & $<0.0001$ \\
& FF(2) & -0.03438 & $<0.0001$ \\
& TOD $(1)$ & -0.00037 & 0.0589 \\
& TOD $(2)$ & -0.00106 & $<0.0001$ \\
& & & \\
& & & \\
& & &
\end{tabular}


Table 5b: The variable coefficients estimated for 100 Monte Carlo simulations of the indicated model, fit with 1000 randomly selected data points, are listed herein. See Table 3 for acronym definitions and variable descriptions.

\begin{tabular}{lllll}
\hline $\begin{array}{l}\text { Model: FVF } \\
\text { Variable }\end{array}$ & INT + FF + MAXWSPD & & & \\
\hline INT & 0.29000 to 0.31100 & 0.30200 & p-value range & p-value mean \\
FF(1) & -0.08300 to -0.06600 & -0.07500 & $<0.0001$ & $<0.0001$ \\
FF(2) & -0.03900 to -0.03100 & -0.03500 & $<0.0001$ & $<0.0001$ \\
MAXWSPD & -0.00060 to 0.00150 & 0.00050 & $<0.0001$ & $<0.0001$ \\
\hline Model: FVF & $=$ INT + FF + MEDWSPD & & & \\
Variable & Coeff. Estimate range & Coeff. Estimate mean & p-value range & p-value mean \\
\hline INT & 0.29260 to 0.30990 & 0.30210 & $<0.0001$ & $<0.0001$ \\
FF(1) & -0.08300 to -0.06850 & -0.07540 & $<0.0001$ & $<0.0001$ \\
FF(2) & -0.04060 to -0.03080 & -0.03530 & $<0.0001$ & $<0.0001$ \\
MEDWSPD & -0.00290 to 0.00120 & -0.00100 & 0.0005 to 0.9970 & 0.3502 \\
\hline Model: FVF $=$ INT + FF + TOD & & & \\
Variable & Coeff. Estimate range & Coeff. Estimate mean & p-value range & p-value mean \\
\hline INT & 0.29140 to 0.30510 & 0.29910 & $<0.0001$ & $<0.0001$ \\
FF(1) & -0.08170 to -0.06630 & -0.07440 & $<0.0001$ & $<0.0001$ \\
FF(2) & -0.04110 to -0.02870 & -0.03450 & $<0.0001$ & $<0.0001$ \\
TOD(1) & -0.00880 to 0.00740 & -0.00030 & 0.0021 to 0.9960 & 0.53 \\
TOD(2) & -0.00920 to 0.00520 & -0.00140 & 0.0015 to 0.9963 & 0.4442
\end{tabular}


Figure 11: Fundamental Vibrational Frequency $(F V F)$ versus maximum wind speed (MAXWSPD) with all data pooled and then separated by the three condition variables: (1) leafon-above-freezing, (2) leaf-off-above-freezing and (3) leaf-off-below-freezing. Note that when separated into conditions, the effect of MAXWSPD on FVF is no longer apparent.

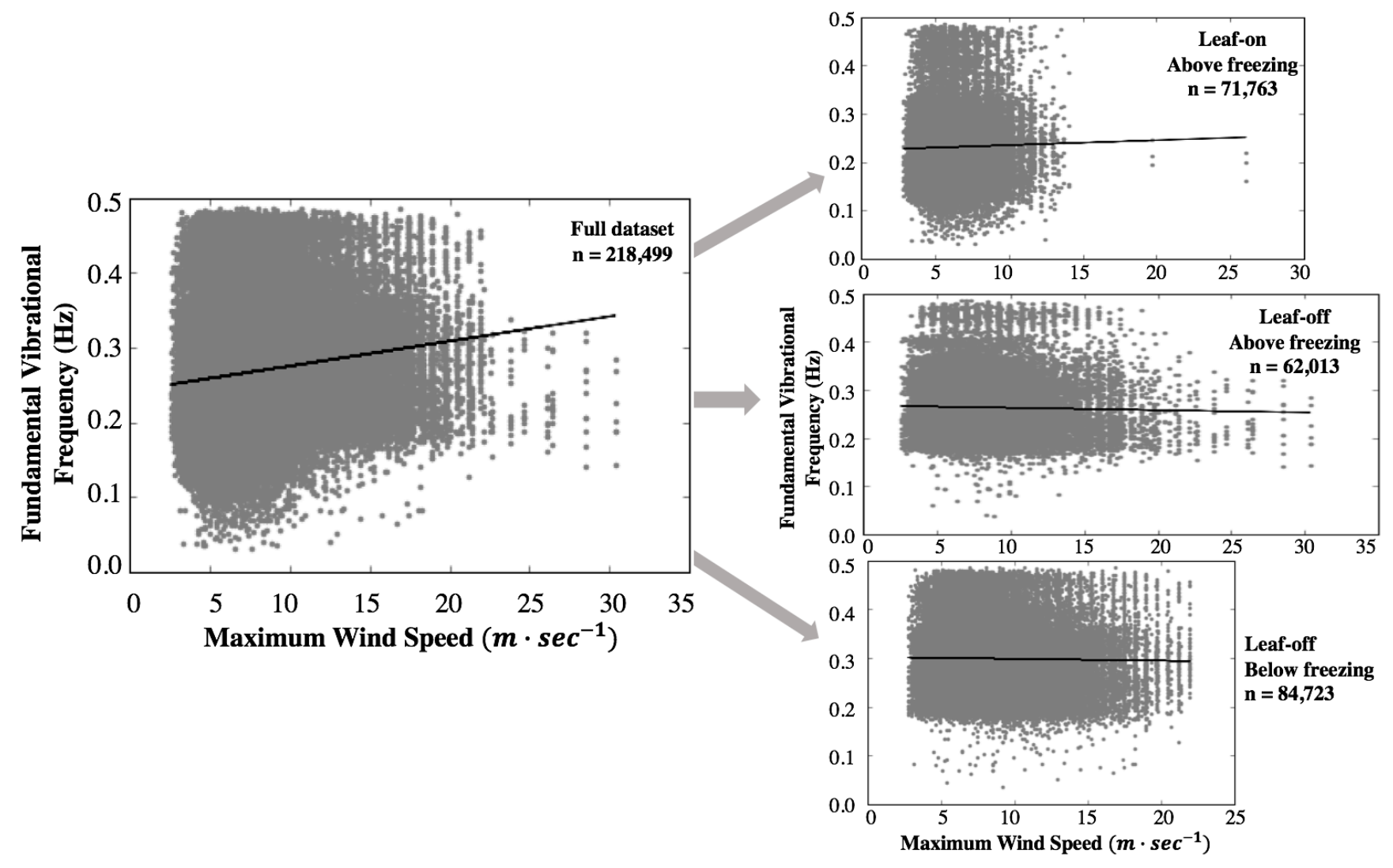


Figure 12: Distribution of maximum wind speed (MAXWSPD) in the three conditions: (1) leafon-above-freezing, (2) leaf-off-above-freezing and (3) leaf-off-below-freezing. Different letters denote significant $(P<0.0001)$ variation in mean MAXWSPD.

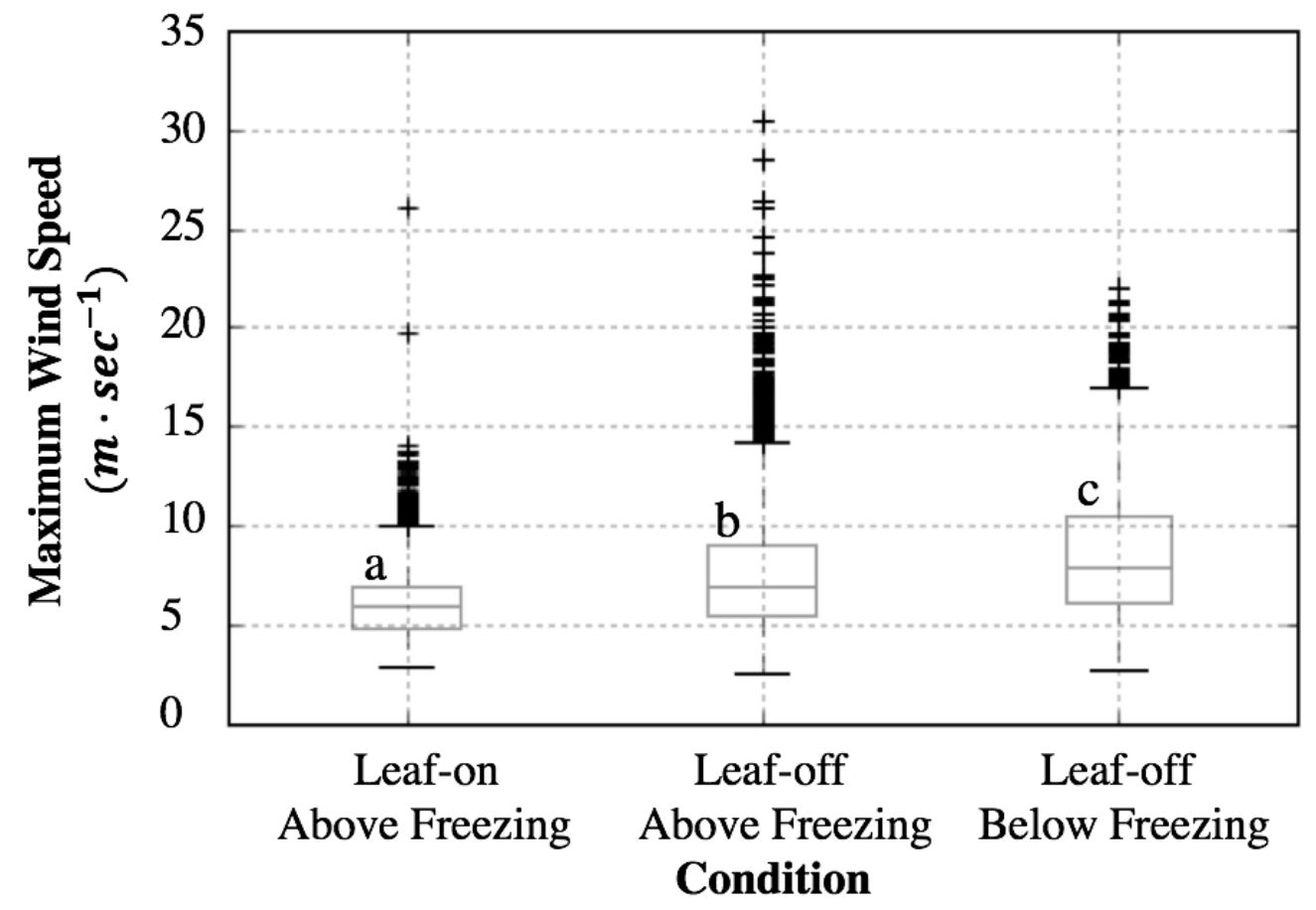


Archer and Jacobson, 2005; Alexidis et al., 1998) in this dataset, wind speeds did not vary between time periods by an amount greater than the precision of the instrumentation (Fig. 13).

Medians of distributions of maximum wind speeds differed by no more than $0.09 \mathrm{~m} \cdot \mathrm{s}^{-1}$ or $0.02 \mathrm{~m} \cdot \mathrm{s}^{-1}$ for median wind speeds. Like MXWPSD and MEDWPSD, when time of day was included in a model with FF, as compared to without FF, its regression coefficient estimates also became closer to zero (Table 5a) and the FF variables remained largely unchanged. Monte Carlo simulations showed that the time of day coefficients, like MAXWPSD and MEDWPSD, ranged over zero and were not significant (Table 5b). As such, the significance of this variable in the model was also not supported.

\subsubsection{Wind Turbulence}

Like the wind speed parameters, the two turbulence measures, standard-deviation-ofwind-speed-from-average (SDWSPD) and maximum-wind-speed-divided-by-average-windspeed $($ MAXOAV), were significantly correlated with FVF $(r=0.18, P<0.0001)$ and $r=0.01, P$ $=0.02$ respectively), but not actually different to a greater degree than the precision of the instrumentation.

In the model FVF $=$ INT + FF + SDWSPD, as compared to the model without SDWSPD, the estimate for the SDWSPD coefficient became a magnitude closer to zero, changing from 0.01863 to -0.00202 , and was no longer significant $(\mathrm{P}>0.05)$ (Table 6a). Similarly, in the model $\mathrm{FVF}=\mathrm{INT}+\mathrm{FF}+\mathrm{MAXOAV}$, as compared to without MAXOAV, the estimate for the MAXOAV coefficient, again became a magnitude closer to zero -0.02188 to -0.00025 and was also no longer significant $(\mathrm{P}=0.28)$ (Table 6a). Like measures of wind speed above, turbulence coefficients ranged over zero and p-values were not consistently significant when the models 
Figure 13: Distribution of maximum (MAXWSPD) and median wind speeds(MEDWSPD) (of 10minute periods) during three time-of-day categories. No differences in medians of the MAXWSPD or MEDWSPD distributions was greater than the precision of the instrumentation.
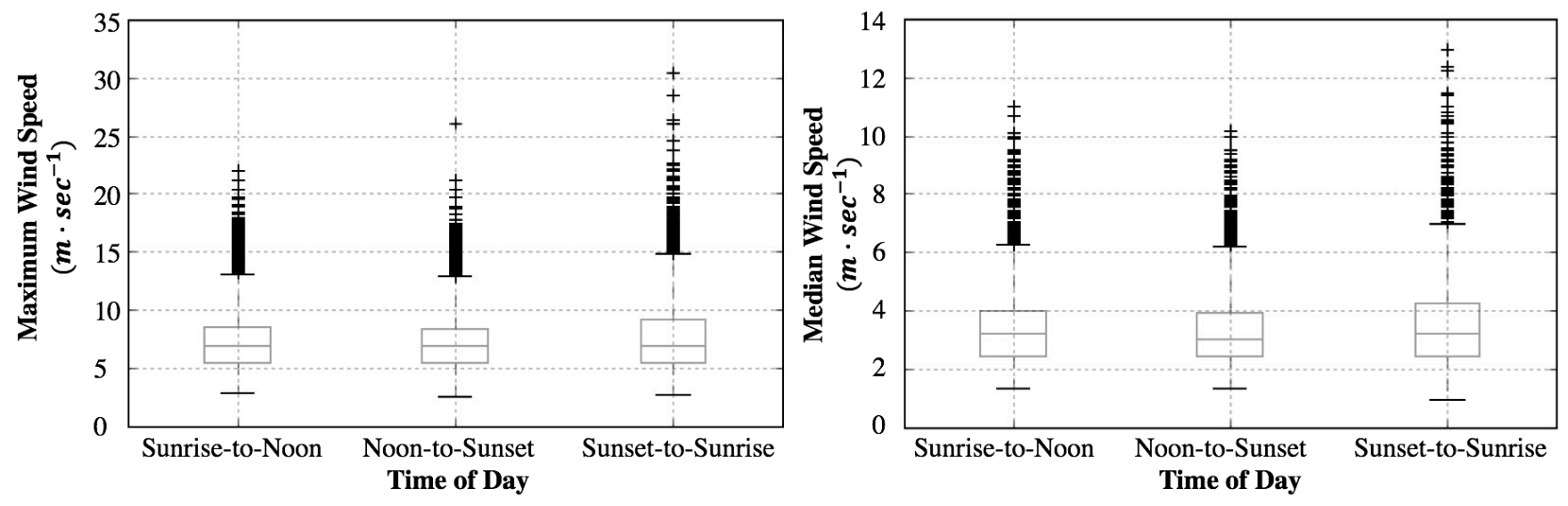
Table 6a: The variable coefficients as estimated for each indicated model, when the model was fit with the entire dataset, are listed herein. See Table 3 for acronym definitions and variable descriptions.

\begin{tabular}{llll}
\hline Model: FVF = INT + SDWSPD & Variable & Coeff. estimate & P-val \\
\hline & INT & 0.2403 & $<0.0001$ \\
& SDWSPD & 0.0186 & $<0.0001$ \\
\hline Model: FVF = INT + FF +SDWSPD & Variable & Coeff. estimate & P-val \\
\cline { 2 - 4 } & INT & 0.3015 & $<0.0001$ \\
& FF(1) & -0.0751 & $<0.0001$ \\
& FF(2) & -0.0351 & $<0.0001$ \\
& SDWSPD & -0.0020 & $<0.0001$ \\
\hline Model: FVF = INT + MXOAV & Variable & Coeff. estimate & P-val \\
\cline { 2 - 4 } & INT & 0.3113 & $<0.0001$ \\
& MXOAV & -0.0219 & $<0.0001$ \\
\hline Model: FVF = INT + FF +MXOAV & Variable & Coeff. estimate & P-val \\
\cline { 2 - 4 } & INT & 0.2990 & $<0.0001$ \\
& FF(1) & -0.0743 & $<0.0001$ \\
& FF(2) & -0.0347 & $<0.0001$ \\
& MXOAV & -0.0003 & 0.2828
\end{tabular}


Table 6b: The variable coefficients estimated for 100 Monte Carlo simulations of the indicated model, fit with 1000 randomly selected data points, are listed herein. See Table 3 for acronym definitions and variable descriptions.

\begin{tabular}{|c|c|c|c|c|}
\hline \multicolumn{5}{|c|}{ Model: FVF = INT + FF + SDWSPD } \\
\hline Variable & Coeff. Estimate range & Coeff. Estimate mean & $\mathrm{p}$-value range & p-value mean \\
\hline INT & 0.2925 to 0.3095 & 0.3010 & $<0.0001$ & $<0.0001$ \\
\hline $\mathrm{FF}(1)$ & -0.0829 to -0.0662 & -0.0748 & $<0.0001$ & $<0.0001$ \\
\hline $\mathrm{FF}(2)$ & -0.0398 to -0.0271 & -0.0350 & $<0.0001$ & $<0.0001$ \\
\hline SDWSPD & -0.0068 to 0.0047 & -0.0017 & 0.0093 to 0.9914 & 0.4471 \\
\hline \multicolumn{5}{|c|}{ Model: $\mathrm{FVF}=\mathrm{INT}+\mathrm{FF}+\mathrm{MXOAV}$} \\
\hline Variable & Coeff. Estimate range & Coeff. Estimate mean & $\mathrm{p}$-value range & p-value mean \\
\hline INT & 0.2738 to 0.3170 & 0.2981 & $<0.0001$ & $<0.0001$ \\
\hline $\mathrm{FF}(1)$ & -0.0808 to -0.0651 & -0.0742 & $<0.0001$ & $<0.0001$ \\
\hline $\mathrm{FF}(2)$ & -0.0402 to -0.0283 & -0.0349 & $<0.0001$ & $<0.0001$ \\
\hline MXOAV & -0.0085 to 0.0119 & 0.0001 & 0.0037 to 0.9563 & 0.4840 \\
\hline
\end{tabular}


were run as Monte Carlo simulations with 1,000 data points (Table 6b). Thus, measures of turbulence, like those of wind speed, do not contribute significantly to explaining FVF.

\subsubsection{Shelter and Support}

The variables shelter and support are measures of both the potential shelter afforded by the surrounding trees on the windward side (SHEL) and the potential support by neighboring trees on the leeward side (SUPP) of the measured tree. Both were positively and significantly (P $<0.0001)$ correlated with FVF in the whole dataset as well as in the three FF categories separately (see Table 7 and Fig. 14).

For the model FVF $=$ INT + SHEL, the estimate of the shelter coefficient was 0.02900, but declined to 0.00900 when FF was included in the model (Table 8a). A similar response was

found in the model FVF = INT + SUPP, where the support coefficient changed from -0.03400 to -0.01500 when FF was added to the model (Table 8a). It is of note that the estimate for support in the model was the opposite sign from what correlation tests suggested. In fact, for several trees, when these correlations were examined by individual trees, they often trended in the opposite direction. In some cases, FVF was negatively correlated with shelter (e.g., tree 2918), while in other situations FVF was negatively correlated with support (e.g., tree 3566) (see Table 9). These inconsistencies, as well as the lessening of the parameters effects on FVF with the inclusion of FF, suggest that the significance of these variables in the model is not supported. This was further reinforced when models including FF and either SHEL or SUPP were run in Monte Carlo simulations with 1,000 data points. The average $\mathrm{P}$-values were not significant $(\mathrm{P}<$ 0.05) for SHEL or SUPP (Table 8b). 
Table 7: Correlations of fundamental vibrational frequency to shelter and support indices are listed herein. The shelter index (SHEL) measures of the presence of canopy trees surrounding a tree of interest in the windward quadrant, where the support index (SUPP) takes the same measurement in the leeward quadrant. The correlations coefficients are listed for the entire dataset, and for the three separate sections of the dataset as divided by the foliage and freezing conditions.

\begin{tabular}{|c|c|c|c|c|}
\hline Data Set & $\begin{array}{l}\text { SHEL } \\
\text { Corr. Coeff. }\end{array}$ & $\begin{array}{l}\text { SHEL } \\
\text { Corr. Coeff. p-value }\end{array}$ & $\begin{array}{l}\text { SUPP } \\
\text { Corr. Coeff. }\end{array}$ & $\begin{array}{l}\text { SUPP } \\
\text { Corr. Coeff. p-value }\end{array}$ \\
\hline All Data & 0.25 & $<0.0001$ & 0.12 & $<0.0001$ \\
\hline Leaves-on, above-freeze & 0.26 & $<0.0001$ & 0.22 & $<0.0001$ \\
\hline Leaves-off, above-freeze & 0.34 & $<0.0001$ & 0.27 & $<0.0001$ \\
\hline Leaves-on, below-freeze & 0.32 & $<0.0001$ & 0.12 & $<0.0001$ \\
\hline
\end{tabular}


Figure 14: The fundamental vibrational frequency is plotted versus shelter and support indicesmeasures of the presence of canopy trees surrounding a tree of interest in the windward quadrant (shelter) or leeward quadrant (support) $(n=218,499)$.
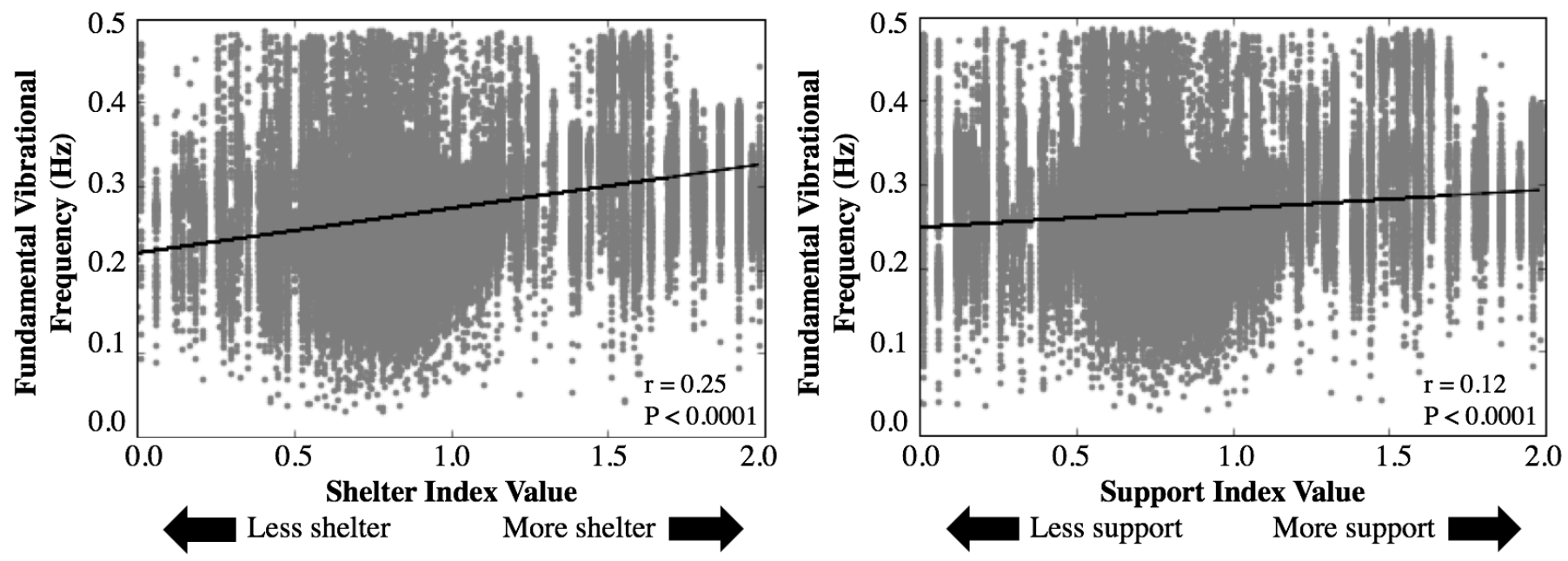
Table 8a: The variable coefficients as estimated for each indicated model, when the model was fit with the entire dataset, are listed herein. See Table 3 for acronym definitions and variable descriptions.

\begin{tabular}{llll}
\hline Model: FVF = INT + SHEL & Variable & Coeff. estimate & P-val \\
\cline { 2 - 4 } & INT & 0.2402 & $<0.0001$ \\
& SHEL & 0.0281 & $<0.0001$ \\
\hline Model: FVF = INT + FF + SHEL & Variable & Coeff. estimate & P-val \\
\cline { 2 - 4 } & INT & 0.2907 & $<0.0001$ \\
& FF $(1)$ & -0.0742 & $<0.0001$ \\
& FF $(2)$ & -0.0346 & $<0.0001$ \\
& SHEL & 0.0088 & $<0.0001$ \\
\hline Model: FVF = INT + SUPP & Variable & Coeff. estimate & P-val \\
\cline { 2 - 4 } & INT & 0.2928 & $<0.0001$ \\
& SUPP & -0.0337 & $<0.0001$ \\
\hline Model: FVF = INT + FF +SUPP & Variable & Coeff. estimate & P-val \\
\cline { 2 - 4 } & INT & .3106 & $<0.0001$ \\
& FF $(1)$ & -0.0740 & $<0.0001$ \\
& FF $(2)$ & -0.0344 & $<0.0001$ \\
& SUPP & -0.0149 & $<0.0001$ \\
\hline
\end{tabular}


Table 8b: The variable coefficients estimated for 100 Monte Carlo simulations of the indicated model, fit with 1000 randomly selected data points, are listed herein. See Table 3 for acronym definitions and variable descriptions.

\begin{tabular}{lllll}
\hline \multicolumn{2}{l}{ Monte Carlo with model FVF $=\mathrm{INT}+\mathrm{FF}+$ SHEL } & & \\
Variable & Coeff. Estimate range & Estimate mean & p-value range & p-value mean \\
\hline INT & 0.2692 to 0.3083 & 0.2859 & $<0.0001$ & $<0.0001$ \\
FF(1) & -0.0821 to -0.0647 & -0.0739 & $<0.0001$ & $<0.0001$ \\
FF(2) & -0.0394 to -0.0293 & -0.0345 & $<0.0001$ & $<0.0001$ \\
SHEL & -0.0106 to 0.0338 & 0.0141 & 0.0002 to 0.9480 & 0.2188 \\
\hline \multicolumn{7}{l}{ Monte Carlo with model FVF $=$ INT + FF + SUPP } & & \\
Variable & Coeff. Estimate range & Estimate mean & p-value range & p-value mean \\
\hline INT & 0.2876 to 0.3249 & 0.3053 & $<0.0001$ & $<0.0001$ \\
FF(1) & -0.0847 to -0.0668 & -0.0740 & $<0.0001$ & $<0.0001$ \\
FF(2) & -0.0401 to -0.0298 & -0.0348 & $<0.0001$ & $<0.0001$ \\
SHEL & -0.0305 to 0.0117 & -0.0081 & 0.0003 to 0.9986 & 0.3814 \\
\hline
\end{tabular}


Table 9: All individual study trees (denoted by their 4-digit tag number) and their Pearsoncorrelation-coefficients $(r)$ of fundamental vibrational frequency $(F V F)$ to shelter and support indices, with relevant level of significance $(P)$. Note that there is no consistency as to whether the effect is positive or negative.

\begin{tabular}{|c|c|c|c|c|}
\hline Tree & r (shelter) & P-value (shelter) & r (support) & P-value (support) \\
\hline 2836 & 0.0590 & $<0.0001$ & 0.0461 & $<0.0001$ \\
\hline 2841 & -0.0905 & $<0.0001$ & 0.1447 & $<0.0001$ \\
\hline 2851 & 0.0101 & 0.3870 & -0.1051 & $<0.0001$ \\
\hline 2852 & 0.0942 & $<0.0001$ & -0.1290 & $<0.0001$ \\
\hline 2853 & 0.0844 & $<0.0001$ & 0.0215 & 0.1199 \\
\hline 2880 & 0.2615 & $<0.0001$ & -0.1309 & $<0.0001$ \\
\hline 2906 & -0.1412 & $<0.0001$ & 0.1778 & $<0.0001$ \\
\hline 2918 & -0.0986 & $<0.0001$ & 0.1721 & $<0.0001$ \\
\hline 2939 & -0.0040 & 0.7678 & -0.0102 & 0.4540 \\
\hline 3042 & 0.1752 & $<0.0001$ & -0.1890 & $<0.0001$ \\
\hline 3087 & 0.1599 & $<0.0001$ & -0.1697 & $<0.0001$ \\
\hline 3132 & 0.0565 & 0.0008 & -0.0342 & 0.0425 \\
\hline 3156 & -0.1693 & $<0.0001$ & 0.2569 & $<0.0001$ \\
\hline 3170 & 0.0362 & 0.0155 & 0.0621 & $<0.0001$ \\
\hline 3176 & 0.0334 & 0.0536 & -0.0718 & $<0.0001$ \\
\hline 3178 & -0.0332 & 0.0371 & -0.1810 & $<0.0001$ \\
\hline 3181 & 0.1231 & $<0.0001$ & 0.2077 & $<0.0001$ \\
\hline 3306 & -0.2442 & $<0.0001$ & 0.2175 & $<0.0001$ \\
\hline 3312 & 0.2630 & $<0.0001$ & -0.0001 & 0.9933 \\
\hline 3328 & -0.1976 & $<0.0001$ & 0.2256 & $<0.0001$ \\
\hline 3359 & -0.2311 & $<0.0001$ & 0.2152 & $<0.0001$ \\
\hline 3399 & -0.1976 & $<0.0001$ & -0.0895 & $<0.0001$ \\
\hline 3400 & 0.2925 & $<0.0001$ & -0.2740 & $<0.0001$ \\
\hline 3431 & -0.0103 & 0.4330 & -0.2897 & $<0.0001$ \\
\hline 3566 & 0.0540 & 0.0359 & -0.0845 & 0.0010 \\
\hline 3910 & 0.2114 & $<0.0001$ & -0.2097 & $<0.0001$ \\
\hline 3920 & 0.2464 & $<0.0001$ & -0.2756 & $<0.0001$ \\
\hline 3944 & 0.1379 & $<0.0001$ & -0.1447 & $<0.0001$ \\
\hline 4133 & 0.0898 & $<0.0001$ & 0.0755 & $<0.0001$ \\
\hline 4187 & -0.0390 & 0.0027 & -0.3831 & $<0.0001$ \\
\hline 4193 & 0.3918 & $<0.0001$ & -0.3912 & $<0.0001$ \\
\hline 4201 & 0.0261 & 0.0872 & 0.2456 & $<0.0001$ \\
\hline 4210 & 0.0752 & $<0.0001$ & 0.0550 & 0.0002 \\
\hline 4218 & 0.1403 & $<0.0001$ & -0.2833 & $<0.0001$ \\
\hline 4230 & 0.2057 & $<0.0001$ & -0.1483 & $<0.0001$ \\
\hline 4246 & -0.1634 & $<0.0001$ & 0.0009 & 0.9562 \\
\hline 4319 & 0.2071 & $<0.0001$ & -0.2531 & $<0.0001$ \\
\hline 4390 & -0.3671 & $<0.0001$ & -0.0556 & 0.0001 \\
\hline 4415 & -0.0390 & 0.0087 & -0.0230 & 0.1221 \\
\hline 4444 & -0.0132 & 0.3898 & 0.0298 & 0.0526 \\
\hline 4669 & 0.3537 & $<0.0001$ & -0.0768 & $<0.0001$ \\
\hline
\end{tabular}




\subsection{Reduction of the dataset}

Given that no wind parameters were found to significantly contribute to the explanation of variance in FVF with foliage present or absent or temperatures above or below freezing (i.e., FF condition), the dataset was reduced. In this case, data were found to be normally distributed for each tree in a given FF condition, thus the dataset was condensed to the average FVF for each tree in each FF condition, resulting in 123 data points (i.e., 41 trees · three FF conditions). These were then used to determine significance for the remaining variables (see 3.3 and 3.4 below).

\subsection{Surrounding forest structure variables}

Basal area (BA) was significantly correlated to $\mathrm{FVF}(\mathrm{r}=-0.32, \mathrm{P}=0.0003)$, while stem density was not (Table 10). The site as a three-level categorical variable (SITE) showed significantly $(\mathrm{P}<0.05)$ lower mean FVF for trees on the Orange site as compared to the other two sites (Fig. 15). However, the addition of any of these three variables to the model did not improve the likeliness of the model to minimize information loss (Table 11).

\subsection{Tree Architecture Variables}

\subsubsection{Height, Diameter at Breast Height and Slenderness}

Total tree height $(\mathrm{H})$ and diameter at breast height $(\mathrm{DBH})$ were both found to be significantly negatively correlated with FVF $(r=-0.45$ and -0.27 respectively) (Table 10$)$. Also, as is typical, both $\mathrm{H}$ and $\mathrm{DBH}$ were strongly correlated with each other $(\mathrm{r}=0.85, \mathrm{P}<0.0001)$.

Comparison of the AIC of the models with each variable, showed that the model with just $\mathrm{H}$ included was most likely to minimize information loss (Table 12), followed by the model with neither H nor DBH included (i.e., FVF = INT + FF), but that model was found to be only $25 \%$ as likely to minimize loss. The most effective candidate model, with solely $\mathrm{H}$, was as follows:

$$
\mathrm{FVF}=\mathrm{INT}+\beta_{1}(\mathrm{FF})+\beta_{2}(\mathrm{H})
$$


Table 10: Pearson correlation coefficients of tree architecture parameters forest structure parameters and crown measurements to fundamental vibrational frequency $(F V F)$ are listed herein. See Table 3 for variable descriptions.

\begin{tabular}{lll}
\hline FVF vs & Corr. Coeff. & P-value \\
\hline Basal Area (BA) & -0.32 & 0.0003 \\
Stem count (STEM) & 0.05 & 0.55 \\
Total tree height (H) & -0.45 & $<0.0001$ \\
Diameter at 1.4m (DBH) & -0.27 & 0.0027 \\
Slenderness calculated as DBH·H ${ }^{-2}$ & 0.35 & $<0.0001$ \\
Slenderness calculated as DBH·H & -0.34 & 0.0001 \\
Slenderness calculated as DD & -0.09 & 0.347 \\
Young's modulus of elasticity (E) & -0.31 & 0.0004 \\
Bending properties (CANT) & 0.28 & $<0.0001$ \\
Crown radius (CRRAD) & -0.08 & 0.38 \\
Crown volume (CRVOL) & -0.21 & 0.02 \\
Crown closure (CRCLO) & -0.03 & 0.73 \\
Height from ground to base of crown (GRTOCR) & -0.4 & $<0.0001$ \\
Height from base of crown to tree top (CRTOTOP) & -0.19 & 0.03 \\
Percentage of total height that is crown (CRHTPER) & 0.12 & 0.18 \\
Symmetry (SYMM) & -0.17 & 0.06 \\
\hline
\end{tabular}


Table 11: Akaike Information Criterion (AIC) values of indicated models, as well as relative AIC score $\left(e^{\frac{\Delta A I C}{2}}\right)$ comparing models to one another are listed herein. See Table 3 for acronym definitions and variable descriptions.

\begin{tabular}{lcc}
\hline Model & AIC & $\boldsymbol{e}^{\frac{\Delta A I C}{2}}$ \\
\hline FVF = INT + FF + SITE & -418.4 & 0.01 \\
FVF = INT + FF + BA & -424.5 & 0.31 \\
FVF = INT + FF + STEM & -418.4 & 0.01 \\
FVF = INT + FF & -426.8 & 1.00 \\
\hline
\end{tabular}


Figure 15: Distributions of fundamental vibrational frequency $(F V F)$ by study site with differing letters indicating significant differences at $P<0.05$ of mean $F V F$.

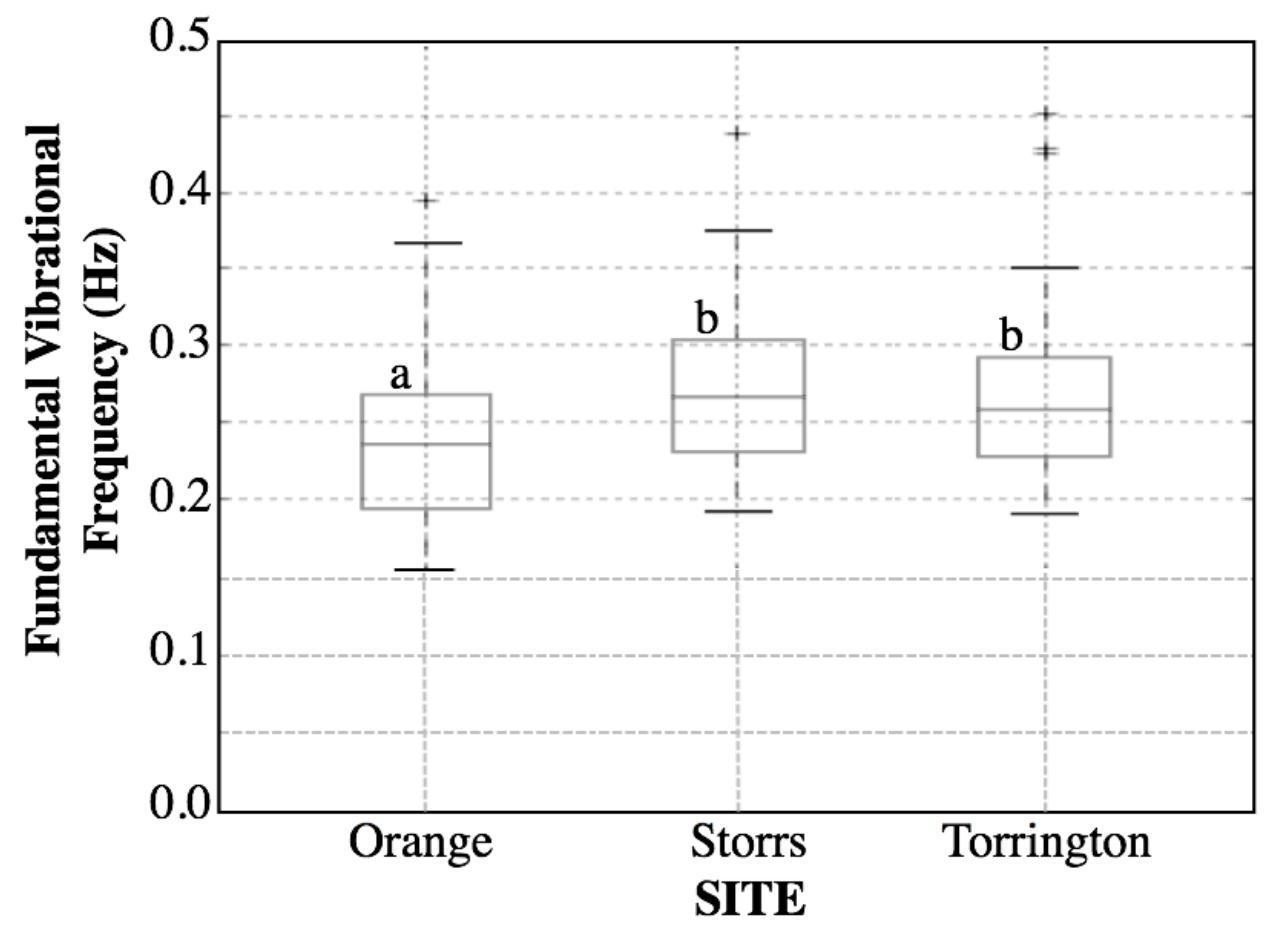


Table 12: Akaike Information Criterion (AIC) values of indicated models, as well as relative AIC score $\left(e^{\frac{\Delta A I C}{2}}\right)$ comparing models to one another are listed herein. See Table 3 for acronym definitions and variable descriptions.

\begin{tabular}{lcc}
\hline Model & AIC & $\boldsymbol{e}^{\frac{\Delta \text { AIC }}{\mathbf{2}}}$ \\
\hline FVF = INT + FF & -426.8 & 0.25 \\
FVF = INT + FF + H & -429.6 & 1.00 \\
FVF $=$ INT + FF + DBH & -418.3 & 0.00 \\
\hline
\end{tabular}


Among the three tree slenderness measures used in this study (i.e., $\mathrm{DBH} \cdot \mathrm{H}^{-2}, \mathrm{DBH} \cdot \mathrm{H}$ and $\Delta \mathrm{D})$, the first two were significantly $(\mathrm{P}<0.001)$ correlated with FVF, while the third was not (Table 10). Comparison of the AIC of the models which incorporated the three tree slenderness variables showed that the model incorporating $\mathrm{DBH} \cdot \mathrm{H}^{-2}$ was the most likely to minimize information loss, with the $\mathrm{H}$ model being the second most likely, but only $14 \%$ as likely to minimize loss (Table 13). Thus, among these candidate models the model incorporating $\mathrm{DBH} \cdot \mathrm{H}^{-2}$ was the strongest predictor of FVF, where:

$$
\mathrm{FVF}=\mathrm{INT}+\beta_{1}(\mathrm{FF})+\beta_{2}\left(\mathrm{DBH} \cdot \mathrm{H}^{-2}\right)
$$

Slenderness is, of course, a function of both $\mathrm{H}$ and $\mathrm{DBH}$. The variable $\mathrm{DBH} \cdot \mathrm{H}^{-2}$ was found to be negatively correlated to $\mathrm{H}(\mathrm{r}=-0.56, \mathrm{P}<0.0001)$. Shorter trees also tended to be the less slender ones $(r=-0.56, \mathrm{P}<0.0001)$. A much weaker correlation was evident with $\mathrm{DBH}(\mathrm{r}=$ $-0.20, P=0.02)$

\subsubsection{Species, Young's Modulus of Elasticity and Cantilever Parameter}

Averaged FVF in the reduced dataset ranged from $0.15-0.45$, and there were significant differences among the eight temperate deciduous and one coniferous tree species used in this study (Fig. 16). However, no one tree species had a significantly different FVF from all others. Even the single coniferous species in this study had an FVF that was not statistically different from two of the eight deciduous species.

Young's modulus of elasticity (E), which is species specific, was significantly negatively correlated with FVF (Table 10) and not surprisingly, the cantilever parameter (CANT), which is a function of $\mathrm{H}, \mathrm{DBH}$ and Young's modulus, was also significantly correlated with FVF (Table 10). Despite these findings, the model with only FF and $\mathrm{DBH} \cdot \mathrm{H}^{-2}$ as fixed effects was considerably (>99\%) more likely to minimize information loss than the same model when either 
Table 13: Akaike Information Criterion (AIC) values of indicated models, as well as relative AIC score $\left(e^{\frac{\Delta A I C}{2}}\right)$ comparing models to one another are listed herein. See Table 3 for acronym definitions and variable descriptions.

\begin{tabular}{lcc}
\hline Model & AIC & $\boldsymbol{e}^{\frac{\Delta \mathrm{AIC}}{2}}$ \\
\hline FVF $=$ INT + FF + H & -429.6 & 0.14 \\
FVF $=$ INT + FF + DBH·H ${ }^{-2}$ & -433.5 & 1.00 \\
FVF $=$ INT + FF + DBH·H & -414.4 & 0.00 \\
FVF $=$ INT + FF + $\mathbf{~ D ~}$ & -421.4 & 0.00 \\
\hline
\end{tabular}


Figure 16: Distributions of fundamental vibrational frequency $(F V F)$ as grouped by species where differing letters indicate significant difference at $P<0.05$ of mean FVF. Species include sugar maple (Acer saccharum), red maple (A. rubrum), black birch (Betula lenta), pignut hickory (Carya glabra), shagbark hickory (C. ovata), red oak (Quercus rubra), white pine (Pinus strobus), black tupelo (Nyssa sylvatica), and yellow poplar (Liriodendron tulipifera).

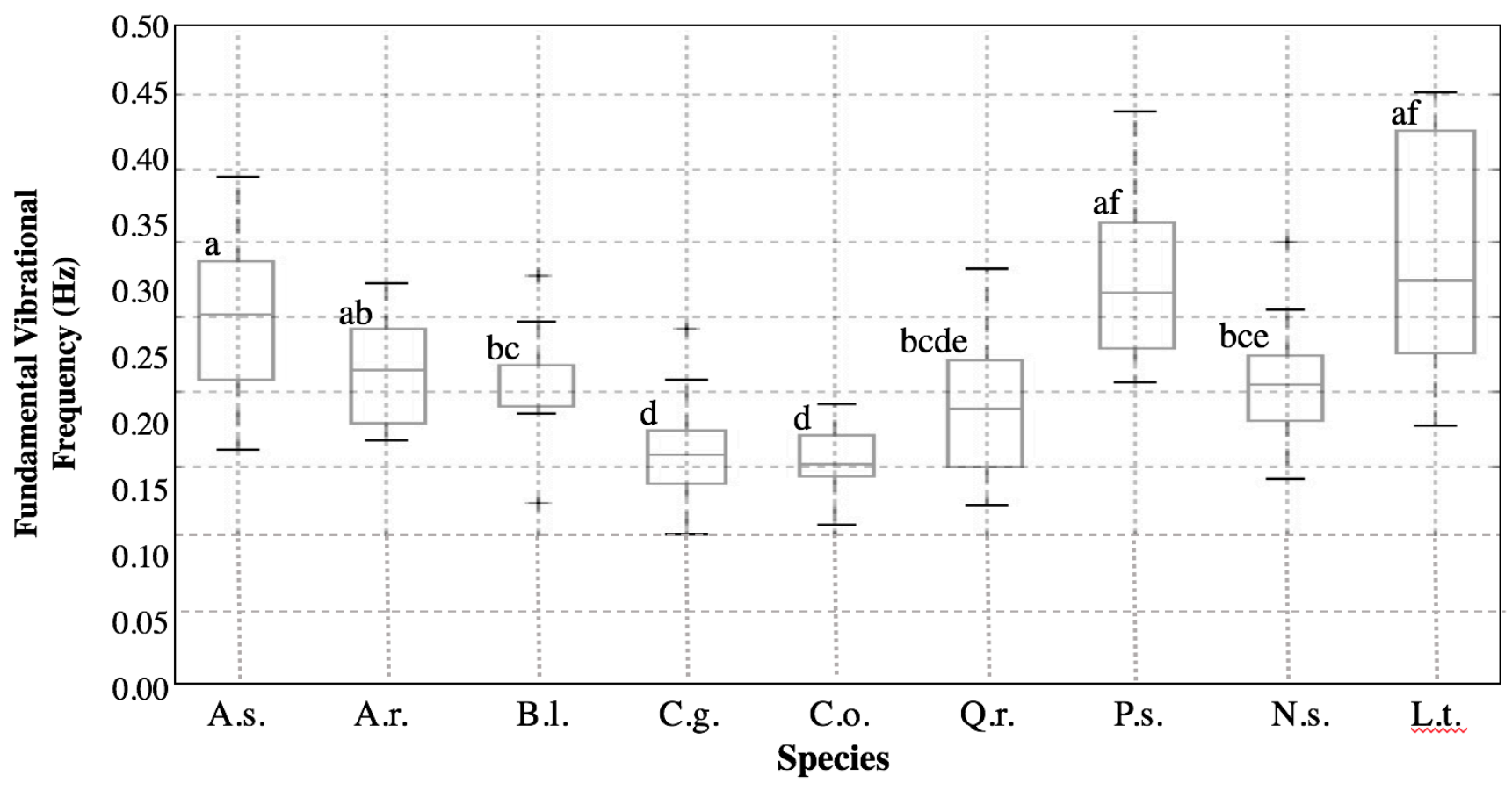


species, E or CANT were included as fixed effects (Table 14). In addition, the interaction variable, $\mathrm{DBH} \cdot$ species, with $\mathrm{DBH} \cdot \mathrm{H}^{-2}$ or without, did not contribute to a better model (Table 13 ).

\subsubsection{Crown parameters}

Of the crown measurement parameters, only ground-to-crown (GRTOCR), crown-to-top (CRTOTOP) and crown volume (CRVOL) were significantly $(\mathrm{r}=-0.4,-0.19$ and $-0.21 ; \mathrm{P}<$ $0.0001,0.03$, and 0.02 , respectively) correlated with FVF (Table 10). However, like the above variables, the addition of any crown parameter did not improve the model's likeliness to minimize information loss (Table 15). The nearest candidate model, one including the crown closure variable, was only $32 \%$ as likely, but crown closure was not significantly correlated to FVF. Crown closure is in fact correlated with $\mathrm{DBH} \cdot \mathrm{H}^{-2}(\mathrm{r}=0.34, \mathrm{P}<0.0001)$ but does not make an effective replacement for $\mathrm{DBH} \cdot \mathrm{H}^{-2}$ in the model (Table 15). Other crown parameters (crown radius, symmetry and percentage of tree height that is live crown) were not significantly correlated to FVF (Table 10), and did not contribute to a more effective model (Table 15). 
Table 14: Akaike Information Criterion (AIC) values of indicated models, as well as relative AIC score $\left(e^{\frac{\Delta A I C}{2}}\right)$ comparing models to one another are listed herein. See Table 3 for acronym definitions and variable descriptions.

\begin{tabular}{lcc}
\hline Model & AIC & $e^{\frac{\Delta \text { AIC }}{2}}$ \\
\hline $\mathrm{FVF}$ = INT + FF + DBH $\cdot H^{-2}$ & -433.5 & 1.00 \\
$\mathrm{FVF}$ = INT + FF + DBH $\cdot H^{-2}+\mathrm{SPEC}$ & -422.6 & 0.00 \\
$\mathrm{FVF}$ = INT + FF + DBH $\cdot \mathrm{H}^{-2}+\mathrm{E}$ & -415.3 & 0.00 \\
$\mathrm{FVF}$ = INT + FF + SPEC & -422.5 & 0.00 \\
$\mathrm{FVF}=\mathrm{INT}+\mathrm{FF}+\mathrm{E}$ & -410.5 & 0.00 \\
$\mathrm{FVF}$ = INT + FF + DBH $\cdot \mathrm{H}^{-2}+(\mathrm{DBH} \cdot \mathrm{SPEC})$ & -412.4 & 0.00 \\
$\mathrm{FVF}=\mathrm{INT}+\mathrm{FF}+(\mathrm{DBH} \cdot \mathrm{SPEC})$ & -406.3 & 0.00 \\
$\mathrm{FVF}$ = INT + FF + CANT & -398.2 & 0.00 \\
$\mathrm{FVF}=\mathrm{INT}+\mathrm{FF}+\mathrm{DBH} \cdot \mathrm{H}^{-2}+\mathrm{CANT}$ & -400.3 & 0.00 \\
\hline
\end{tabular}


Table 15: Akaike Information Criterion (AIC) values of indicated models, as well as relative AIC score $\left(e^{\frac{\Delta A I C}{2}}\right)$ comparing models to one another are listed herein. See Table 3 for acronym definitions and variable descriptions.

\begin{tabular}{lll}
\hline Model & AIC & $e^{\frac{\Delta \text { AIC }}{2}}$ \\
\hline FVF $=$ INT + FF + DBH $\cdot H^{-2}$ & -433.5 & 1.00 \\
$\mathrm{FVF}$ = INT + FF + DBH $\cdot H^{-2}+$ GRTOCR & -428.7 & 0.09 \\
$\mathrm{FVF}$ = INT + FF + DBH $\cdot H^{-2}+\mathrm{CRTOTOP}$ & -422.9 & 0.00 \\
$\mathrm{FVF}$ = INT + FF + DBH $\cdot \mathrm{H}^{-2}+\mathrm{CRHTPER}$ & -429.3 & 0.12 \\
$\mathrm{FVF}$ = INT + FF + DBH $\cdot \mathrm{H}^{-2}+\mathrm{SYMM}$ & -424.0 & 0.01 \\
$\mathrm{FVF}$ = INT + FF + DBH $\cdot \mathrm{H}^{-2}+\mathrm{CRRAD}$ & -422.9 & 0.00 \\
$\mathrm{FVF}$ = INT + FF + DBH $\cdot \mathrm{H}^{-2}+\mathrm{CRVOL}$ & -414.6 & 0.00 \\
$\mathrm{FVF}$ = INT + FF + DBH $\cdot \mathrm{H}^{-2}+\mathrm{CRCLO}$ & -431.2 & 0.32 \\
$\mathrm{FVF}$ = INT + FF + CRCLO & -423.4 & 0.01 \\
\hline
\end{tabular}




\subsection{Final Model}

After testing for all 27 parameters, the most effective model for predicting FVF across a diversity of tree species within closed canopy temperate deciduous forests included whether foliage is present or absent, whether conditions were above or below freezing and a measure of tree slenderness, specifically $\mathrm{DBH} \cdot \mathrm{H}^{-2}$ :

$$
\mathrm{FVF}=\mathrm{INT}+\beta_{1}(\mathrm{FF})+\beta_{2}\left(\mathrm{DBH} \cdot \mathrm{H}^{-2}\right)
$$

The model fit to this data set is:

$$
\begin{gathered}
F V F=0.18840+\mathrm{FF}_{1}(-0.07459)+\mathrm{FF}_{2}(-0.03322)+\left(\mathrm{DBH} \cdot \mathrm{H}^{-2}\right)(1.52460) \\
\left(\mathrm{R}^{2}=0.48, \mathrm{RMSE}=0.04356\right)
\end{gathered}
$$

The final model was fit without tree \# 3566, which proved to be an extreme outlier. This tree does not truly count as a closed-canopy tree as it is located on the corner of a stand, so was mostly open-grown. Trees on an edge were not outliers in the data. 


\subsection{Discussion}

\subsection{Foliage Condition and Freezing Temperatures}

In support of my first hypothesis, I found that FVF increased when foliage was not present and when ambient temperatures were below $-5^{\circ} \mathrm{C}$. This response is in keeping with findings of previous analyses. For instance, two studies found that removal of needles and branches of coniferous species, if the removal was significant enough, resulted in increased FVF (Moore and Maguire, 2005; Sellier and Fourcaud, 2005). Although it has not been studied extensively in species of deciduous trees, some studies have shown FVF to also be lower when a deciduous tree was in-leaf (Baker, 1997; Schindler et al., 2013). The effect of below-freezing temperatures on FVF in deciduous tree species is minimal in the literature, but like my findings, Granucci et al. (2013) found below freezing temperatures to increase FVF, due to stiffening of the bole for coniferous trees in Maine, USA.

\subsection{Wind Speed and Fluctuation in Speed}

My second hypothesis, that the intensity or direction of the wind will not be effective predictors of FVF was also supported. I examined maximum wind speed, median wind speed, and time of day and none of these variables were found to be significant predictors of FVF which is consistent with Webb et al. (2013). I hypothesized that FVF should not vary with the force applied to a tree (i.e., the wind in this case) in much the same way that the frequency of a tuning fork remains consistent despite variation in the force with which it is struck. On the other hand, variation in wind speed could possibly alter the tree architecture, thus potentially altering FVF, as some species reorient in either leaf shape (Vogel, 1989) or whole tree form (Miller, 2005; Rudnicki et al., 2004) into configurations that lessen the drag in a process called streamlining. 
However, while drag affects the time it takes for motion to dampen (Baker, 1995; Milne, 1991), my study does not show that it directly affects the FVF.

The wind force pulses against a tree with a frequency of its own (Wood, 1995). While I was unable to measure wind turbulence directly (see Baker, 1995; for example where turbulence was modeled; Sellier and Fourcaud, 2009), I did examine fluctuation of wind speed in two variables; the standard deviation of wind speed and the ratio of maximum wind speed to mean wind speed. Several sway studies have suggested a tree becomes most susceptible to wind throw when the frequency of the wind approaches the FVF of the tree (Peltola, 1996; James, 2006; Rodriguez et al., 2012). This implies that FVF of the tree remains constant with changing winds, which is consistent with my findings.

When wind and tree frequencies approach one another, resonance can cause an exponential increase in sway amplitude (Peltola,1996; Spatz et al., 2007). Branches, which move at their own frequency but are coupled to each other and to the trunk, will alter FVF, avoiding resonance with the wind (James, 2006; Theckes et al., 2011; Rodriguez et al., 2012; Spatz et al., 2013). This mechanistic phenomenon again does not suggest that FVF of the tree changes with the wind, only that it is developed in such a way that precludes resonance with the wind.

Gardiner et al. (1997) suggested that as a tree develops, the closer its mean experienced wind speed is to the maximum wind speeds experienced, the better adapted a tree will be to withstand the wind regime. This again suggests that FVF of the tree is not subject to variation in a changing wind speed or level of fluctuation in wind, but only to the long-term wind regime wherein the tree grows and thus develops a unique FVF. This idea is supported by my findings where variables measuring speed or fluctuation in wind speed were not predictive of FVF among the nine species studied. 


\subsection{Shelter and Support}

Wind direction did not have an effect on variation in FVF in my study, as has been found consistently in literature. In sway studies where trees were mechanically set in motion, the direction of the pull has been found to make no significant differences in the resulting FVF of the tree (Mayer, 1987; Milne, 1991; Moore and Maguire, 2005; Kane et al., 2014), even where it was known that the roots of the tree were unbalanced (Jonsson, 2007). Wind direction may affect wind loading as wind penetrates the canopy from above (Gardiner et al., 1997), forming eddies which have a force directly related to the size of the gap in which they form (Finnigan and Brunet, 1995). However, as explained above, force on the tree will not affect FVF. Despite this, my third hypothesis was that the structure of the neighboring canopy would affect FVF and this assertion was based on the interactions with neighboring trees and not because of eddy formation. It has been suggested that FVF varies with variation in collision with neighboring trees (Milne, 1991; Moore and Maguire, 2005; Rudnicki et al., 2008). Although, contradictions in the way these collisions affect FVF have been found (Webb et al., 2013).

I used an index of shelter from incoming wind based on a function of surrounding trees and wind direction as well as an index of support by neighboring trees. These two variables allowed me to test the variation in FVF with variation in collisions and gaps around the measured tree, however, neither variable was found to appreciably help explain the variation in the model for FVF. These findings add to the growing evidence from studies that have found FVF to be unaffected by force direction (e.g., Mayer, 1987; Milne, 1991; Moore and Maguire, 2005; Jonsson, 2007; Kane et al., 2014).

On the other hand, these findings also do not contradict the notion that FVF may vary with collision intensity. In other words, it suggests that the surrounding forest architecture is 
effectively a part of the structure of the tree in question, and the tree does not move wholly independently. In this study, I have found trees do not sway back-and-forth, but rather tend to sway in a more circular pattern (sensu Peltola (1996) who noted that the trees do not return to a central point while swaying) (data not shown). In this way, the architectural elements of the whole space (i.e., all neighboring trees and gaps) interact, and not just the wedges of surrounding space pertaining to the current wind direction. Webb et al. (2013) noted an apparent change in tree stiffness when neighboring trees were removed, and referred to this as effective flexural stiffness. In this study, the shelter and support variables were not significant in the predictive model; however, the indices developed for this study have not been investigated in any other context, and further study is needed to investigate the potential for forest structure of the whole surrounding space to drive FVF.

\subsection{Surrounding Forest Structure}

While basal area was correlated with FVF, stem density was not, however, neither variable improved the models likeliness to minimize loss of information. This was in contrast to my fourth hypothesis wherein I expected that, because of established correlations of basal area and stem density with tree architecture, those measurements would in fact be predictive of FVF. It was surprising that basal area was not effective even in a model lacking the $\mathrm{DBH} \cdot \mathrm{H}^{-2}$ term, as

the two are strongly correlated. Moreover, FVF has been found to increase with a spacing: height ratio (Gardiner, 1997), and it is well established that spacing influences stem form (Larson, 1963; Holbrook and Putz, 1989; Baldwin et al., 2000). In this study, it may be that among the three sites studied that the range in basal area and stem density were not sufficiently variable to capture potential differences or interactions. For instance, the Torrington and Orange sites had exactly the same basal area, Storrs and Orange had similar stem densities, and Torrington and 
Storrs had statistically equal FVF means. Thus, it remains inconclusive as to the potential that surrounding forest structure variables may or may not affect FVF and warrants future study.

It is of note that for both basal area and stem density, the coefficients did not approach zero when the variable denoting foliage and freezing conditions (FF) was added to the model, while coefficients for all of the wind speed variables did. Wind speed variables did approach zero because the amount of variation in FVF that they represented was accounted for in the FF term. Thus, while basal area and stem density were insignificant in the model, these two variables may actually play a role in overall FVF at a stand level. However, as mentioned above further studies are needed to elucidate these potential interactions.

Among the three sites studied, I found no significant site effect on FVF, which was not unexpected. Posada et al. (2009) also found no site variables (including altitude, mean slope and aspect) to be significant in a model predicting tree susceptibility to wind throw and the site conditions in that study differed substantially more than in this study.

\subsection{Tree architecture parameters}

It was unexpected that the addition of DBH did not improve a model with the FF variable only. DBH is a key variable for computing tree slenderness, and slenderness has been found to predict FVF in a number of studies (see review by Moore and Maguire, 2004). Accounting for species did not improve the model, nor did the interaction of DBH*species. Nolet et al. (2012) found variation in wind throw susceptibility with DBH varied by species. The interactions ineffectiveness in this study suggests further study of the relationship of FVF and risk of wind throw is needed.

Along with DBH, the height of a tree is also critical in calculating slenderness, and indeed, the height variable in my study did improve the model. Together, the two variables form 
a measurement of slenderness commonly used to estimate FVF of conifers, namely $\left(\mathrm{DBH} \cdot \mathrm{H}^{-2}\right)$

(Moore and Maguire, 2004; Jonsson, 2007), which, in this study, improved the model more effectively than height alone. It may be that it is not the size of the tree itself, but more its relative proportions that drive FVF. In this study, shorter trees also tended to be the less slender ones, where a much weaker correlation was evident with DBH.

The significance of $\mathrm{DBH} \cdot \mathrm{H}^{-2}$ as a predictor of $\mathrm{FVF}$ was unexpected because the architectural growth and development of deciduous broad-leaved trees is markedly different from that of conifers (i.e. excurrent versus decurrent branching habits). However, both types of trees tend to be tall and form branching only at the top when grown in a closed canopy, making the trees in this study more similar to previously studied conifers than they would be if they had been open-grown. A study by Kane et al. (2014) showed $\mathrm{DBH} \cdot \mathrm{H}^{-2}$ to not be effective in predicting FVF, but the trees in that study were open grown maples whose shape was dramatically stouter than the closed canopy forest trees in this study.

In this study, Young's modulus of elasticity (E), which is a measurement defining the relationship of tensile stress to strain in a solid material under a load from which it can completely recover (Green et al., 1999), was also not predictive. Granucci et al. (2013) found that freezing leads to stiffening (i.e., increase E) which results in a higher FVF. In my study, E corresponded to a specific species, under non-freezing conditions, which likely precluded E having an effect on FVF, underscored by the fact that species as a parameter was not an effective predictor.

We expected an architectural parameter describing the crown to be effective in the model, and not $\mathrm{DBH} \cdot \mathrm{H}^{-2}$, the architectural parameter commonly found to predict $\mathrm{FVF}$ in coniferous plantation trees. In studies done on deciduous broad-leaved trees, which the majority of trees in 
this study were, crown parameters have been shown to be significant predictors of FVF (see Kane et al., 2014; Baker, 1997). In a mathematical exercise, as well, modeling probability of failure, Ciftci et al. (2014) found the frontal area of the crown, the area exposed to the wind, to be an important predictor of FVF. In another study examining a group of highly branched deciduous trees, FVF was dependent on a crown parameter (i.e., cumulative branch diameter) (Kane et al., 2014). Although, it should be noted that this correlation was no longer significant if the two most heavily branched trees were removed from the study. Moore and Maguire (2005) found that FVF variation with branch removal in a coniferous species varied depending on tree slenderness, finding that FVF is more dependent on branching for less slender trees. Taken together, all of these findings suggest that there may be a threshold of branch mass where FVF is predictable by crown parameters, but below such a threshold, slenderness is the driving factor. This supports the findings in my study of closed-canopy conditions where trees have a much lower proportion of branch to stem allocation than open grown conditions would create, and I found FVF is more predictable by a trees' slenderness than by any crown parameter measured.

\subsection{Forest Management Implications}

In this study, variation in FVF of trees in closed canopy roadside temperate deciduous forests was primarily explained by tree slenderness. While the relationship between FVF and wind-firmness needs further investigation, theory suggests that trees with higher FVFs tend to be more wind firm (Mayer 1987; Baker, 1995), thus roadside forests would benefit from management that would lessen slenderness. Such management has the potential to promote wind-firmness in trees. In addition, this type of management will inherently lessen stand density and competition among trees. The ones that are selected for will have greater access to resources causing them to be more able to withstand pests, diseases and climate-related stressors. Also, 
with the canopy-opening that coincides with wind exposure, trees would have the opportunity to grow symmetrically and thusly be less mechanically stressed as well.

Forest management techniques can leverage relationships between slenderness and other features to promote a desired slenderness that would translate to greater wind-firmness. Many studies have drawn correlations of the slenderness coefficient (predominantly defined as the ratio $\mathrm{H}: \mathrm{DBH}$ ) to attributes of tree or stand. Smaller slenderness coefficients (which would equate to a larger $\mathrm{DBH} \cdot \mathrm{H}^{-2}$ and an increased $\mathrm{FVF}$ ) are correlated to larger crown lengths, more advanced ages, and lesser relative stand densities (Wang et. al, 1998). Rudnicki et al. (2004) found in stands of lodgepole pine over heights of $15 \mathrm{~m}$, percent crown cover was negatively correlated with the slenderness coefficient. Crown position has been found to be negatively correlated with slenderness and slenderness to vary among species (Harja et al., 2012). This study had weak, but significant correlations of H: DBH with Young's modulus of elasticity, ground-to crown and crown-to-top measurements, and some significant $(\mathrm{P}>0.05)$ variation with variation among species.

The individual tree allometric relationships and forest condition features (stand age and species mix) that result in smaller slenderness coefficients can be achieved with intermediate forest management treatments (i.e., canopy and low-level thinning). Management intended to foster these features could help to improve the wind-firmness of forested areas. Such management could be applied to northeastern temperate deciduous roadside forests to address many of the aforementioned concerns that result in the failure of trees and subsequent threat to utility infrastructure in densely populated areas that also have a large percentage of forest cover. 


\subsection{Future Directions}

This study could be expanded to include supplementary sites that would present more effective variation in forest structure parameters (BA and STEM). Additionally, further investigation into the relationship of sway (FVF and sway amplitude) to risk-of-windthrow would contribute greatly to the application of biomechanics information. Available information is minimal and not often empirical. This study is intended to be part of a comprehensive look at the biomechanics of the trees of the Northeast temperate deciduous mixed roadside forests. In addition to FVF, a predictive model elucidating the drivers of sway amplitude (a.k.a. bole displacement) from the same set of potential parameters is also in development. The second phase of the larger study will look at changes in FVF and sway amplitude in response to forest management treatments over a multiple-year time frame. 


\subsection{Conclusions}

The best predictive model derived of the 27 tested variables was determined to be:

$$
\mathrm{FVF}=\mathrm{INT}+\beta_{1}(\mathrm{FF})+\beta_{2}\left(\mathrm{DBH} \cdot \mathrm{H}^{-2}\right)
$$

The most extensive research on tree sway has occurred in coniferous plantations stands, and has found $\mathrm{DBH} \cdot \mathrm{H}^{-2}$ to be predictive of $\mathrm{FVF}$. This study in the northeastern temperate deciduous forest has come to the same conclusion, suggesting that regardless of species mix, management history, or other differing site conditions, slenderness is the dominant determining factor of FVF for trees grown in a closed-canopy condition. 


\subsection{Resources}

AASHTO, LTS. (2013) Standard Specifications for Structural Supports for Highway Signs. Luminaires and Traffic Signals.

Alexiadis, M. C., P.S. Dokopoulos, H.S. Sahsamanoglou, I.M. Manousaridis (1998) Short-term forecasting of wind speed and related electrical power. Solar Energy 63.1: 61-68

Archer, Cristina L., and Mark Z. Jacobson (2005) Evaluation of global wind power. Journal of Geophysical Research: Atmospheres 110.D12

Ashby, W. Clark, Clay A. Kolar, Thomas R. Hendricks, and Robert E. Phares (1979) Notes: Effects of Shaking and Shading on Growth of Three Hardwood Species. Forest Science 25.2: 212-216.

Baker, C. J. (1995) The development of a theoretical model for the windthrow of plants. Journal of Theoretical Biology 175.3: 355-372.

Baker, C. J. (1997) Measurements of the natural frequencies of trees. Journal of Experimental Botany 48.5: 1125-1132.

Baldwin, V. Clark, Kelly D. Peterson, Alexander Clark, Robert B. Ferguson, Mike R. Strub, and David R. Bower (2000) The effects of spacing and thinning on stand and tree characteristics of 38-year-old loblolly pine. Forest Ecology and Management 137.1: 91-102.

Bean, Allan, Robert W. Alperi, and C. A. Federer (1974) A method for categorizing shelterbelt porosity. Agricultural Meteorology 14.1-2: 417-429.

Bender, Morris A., Thomas R. Knutson, Robert E. Tuleya, Joseph J. Sirutis, Gabriel A. Vecchi, Stephen T. Garner, and Isaac M. Held (2010) Modeled impact of anthropogenic warming on the frequency of intense Atlantic hurricanes. Science 327.5964: 454-458.

Bromley, Stanley W. (1935) The original forest types of southern New England. Ecological Monographs 5.1: 61-89.

Butler, Brett J., Charles J. Barnett, Susan J. Crocker, Grant M. Domke, Dale Gormanson, William N. Hill, Cassandra M. Kurtz (2011) The forests of Southern New England, 2007: a report on the forest resources of Connecticut, Massachusetts, and Rhode Island.

Cieslewicz, Stephen R. and Novembri, Robert R. (2004) Utility Vegetation Management Final Report. http://www.ferc.gov/industries/electric/indus-act/reliability/blackout/uvm-final-report.pdf. Accessed May 03, 2016.

Chehab, E. Wassim, Elizabeth Eich, and Janet Braam (2009) Thigmomorphogenesis: a complex plant response to mechano-stimulation. Journal of Experimental Botany 60.1: 43-56.

Chen, Jing M., Paul Steven Plummer, M. Rich, Stith T. Gower, and John M. Norman (1997) Leaf area index measurements." Journal of geophysical research 102.D24: 29-429.

Ciftci, C., Arwade, S. R., Kane, B., \& Brena, S. F. (2014) Analysis of the probability of failure for opengrown trees during wind storms. Probabilistic Engineering Mechanics 37: 41-50. 
Cordero, Roberto A. (1999) Ecophysiology of Cecropia schreberiana saplings in two wind regimes in an elfin cloud forest: growth, gas exchange, architecture and stem biomechanics. Tree Physiology 19.3: 153-163.

Dale, Virginia H., Linda A. Joyce, Steve McNulty, Ronald P. Neilson, Matthew P. Ayres, Michael D. Flannigan, Paul J. Hanson (2001) Climate change and forest disturbances: climate change can affect forests by altering the frequency, intensity, duration, and timing of fire, drought, introduced species, insect and pathogen outbreaks, hurricanes, windstorms, ice storms, or landslides. BioScience 51.9: 723-734.

Deric, Miki and Hollenbaugh, Rick (2003) Vegetation Managers Weigh Costs Against Performance. T\&D World Magazine. http://tdworld.com/reliability-amp-safety/vegetation-managers-weighcosts-against-performance. Accessed 05-03-2016.

Dreiss, Lindsay M., and John C. Volin (2013) Influence of leaf phenology and site nitrogen on invasive species establishment in temperate deciduous forest understories. Forest Ecology and Management 296: 1-8.

Emanuel, Kerry (2005) Increasing destructiveness of tropical cyclones over the past 30 years. Nature 436.7051: 686-688.

England, A. H., C. J. Baker, and S. E. T. Saunderson (2000) A dynamic analysis of windthrow of trees. Forestry 73.3: 225-238.

Finnigan, J. J., and Y. Brunet (1995) Turbulent airflow in forests on flat and hilly terrain. In: Wind and trees Cambridge University Press, Cambridge, pp. 3-40.

Foster, David R. (1992) Land-use history (1730-1990) and vegetation dynamics in central New England, USA. Journal of ecology: 753-771.

Foster, David R., Glenn Motzkin, and Benjamin Slater (1998) Land-use history as long-term broad-scale disturbance: regional forest dynamics in central New England. Ecosystems 1.1: 96-119.

Gardiner, B. A. (1995) The interactions of wind and tree movement in forest canopies. In: Wind and trees. Cambridge University Press, Cambridge, pp. 41-59.

Gardiner, B. A., C. J. Wood, R. E. Belcher, and G. R. Stacey. (1997) Field and wind tunnel assessments of the implications of respacing and thinning for tree stability. Forestry: An International Journal of Forest Research 70.3.

Granucci, David, Mark Rudnicki, April Hiscox, David Miller, and Hong-Bing Su (2013) Quantifying the effects of freezing on tree sway frequencies. Agricultural and forest meteorology 168: 10-14.

Green, D. W., J. E. Winandy, and D. E. Kretschmann (1999) Mechanical properties of wood-wood as an engineering material. General Technical Report FPL-TR 113.

Harja, Degi, Grégoire Vincent, Rachmat Mulia, and Meine van Noordwijk (2012) Tree shape plasticity in relation to crown exposure. Trees 26.4: 1275-1285. 
Holbrook, N. Michele, and Francis E. Putz. (1989) Influence of neighbors on tree form: effects of lateral shade and prevention of sway on the allometry of Liquidambar styraciflua (sweet gum). American journal of Botany: 1740-1749.

Jaffe, M. J. (1973) Thigmomorphogenesis: the response of plant growth and development to mechanical stimulation. Planta 114.2: 143-157.

Jaffe, M. J. (1980) Morphogenetic responses of plants to mechanical stimuli or stress. Bioscience 30.4: 239-243.

Jaffe, M. J., and S. Forbes (1993) Thigmomorphogenesis: the effect of mechanical perturbation on plants. Plant Growth Regulation 12.3: 313-324.

James, Kenneth R., Nicholas Haritos, and Peter K. Ades. (2006) Mechanical stability of trees under dynamic loads. American journal of Botany 93.10: 1522-1530.

Jonsson, M. J., A. Foetzki, M. Kalberer, T. Lundström, W. Ammann, and V. Stöckli. (2007) Natural frequencies and damping ratios of Norway spruce (Picea abies (L.) Karst) growing on subalpine forested slopes. Trees 21.5: 541-548.

Kane, Brian, Yahya Modarres-Sadeghi, Kenneth R. James, and Mark Reiland (2014) Effects of crown structure on the sway characteristics of large decurrent trees. Trees 28.1: 151-159.

Kittredge, David B., and P. Mark S. Ashton (1995) Impact of deer browsing on regeneration in mixed stands in southern New England. Northern Journal of Applied Forestry 12.3: 115-120.

Larson, Philip R. (1963) Stem form development of forest trees. Forest science 9.4: a0001-a0001.

Lin, Mingfeng, Henry C. Lucas Jr, and Galit Shmueli (2013) Research commentary - too big to fail: large samples and the p-value problem. Information Systems Research 24.4: 906-917.

Lovett, Gary M., Charles D. Canham, Mary A. Arthur, Kathleen C. Weathers, and Ross D. Fitzhugh (2006) Forest ecosystem responses to exotic pests and pathogens in eastern North America. BioScience 56.5: 395-405.

Macfarlane, Craig, Megan Hoffman, Derek Eamus, Naomi Kerp, Simon Higginson, Ross McMurtrie, and Mark Adams (2007) Estimation of leaf area index in eucalypt forest using digital photography. Agricultural and forest meteorology 143.3: 176-188.

Mayer, Hi. (1987) Wind-induced tree sways. Trees-Structure and Function 1.4: 195-206.

McGee, Joe, James Skiff, Peter Carozza, Terry Edelstein, Lee Hoffman, Scott Jackson, Robert McGrath and Catherine Osten (2012) Report of the two-storm panel; presented to governor Dannel P. Malloy. http://portal.ct.gov/en/Office-of-the-Governor/Working-Groups/Two-Storm-Panel. Accessed 08-14-2017.

Miller, Laura A. (2005) Structural dynamics and resonance in plants with nonlinear stiffness. Journal of theoretical biology 234.4: 511-524.

Milne, Ron (1991) Dynamics of swaying of Picea sitchensis. Tree Physiol 9.3: 383-399. 
Moore, John R. (2000) Differences in maximum resistive bending moments of Pinus radiata trees grown on a range of soil types. Forest Ecology and Management 135.1: 63-71.

Moore, John R., and Douglas A. Maguire (2004) Natural sway frequencies and damping ratios of trees: concepts, review and synthesis of previous studies. Trees 18.2: 195-203.

Moore, John R., and Douglas A. Maguire. (2005) Natural sway frequencies and damping ratios of trees: influence of crown structure. Trees 19.4: 363-373.

Murcia, Carolina (1995) Edge effects in fragmented forests: implications for conservation. Trends in ecology \& evolution 10.2: 58-62.

Nolet, Philippe, Frédérik Doyon, and Daniel Bouffard (2012) Predicting stem windthrow probability in a northern hardwood forest using a wind intensity bio-indicator approach. Open Journal of Forestry 2.02: 77 .

Nowak, D.J. and Greenfield, E.J. (2008) Urban and community forests of New England: Connecticut, Maine, Massachusetts, New Hampshire, Rhode Island, Vermont. Gen. Tech. Rep. NRS-38. Newtown Square, PA: U.S. Department of Agriculture, Forest Service, Northern Research Station. $62 \mathrm{pp}$.

O'Brien, Sean T., Stephen P. Hubbell, Peter Spiro, Richard Condit, and Robin B. Foster (1995) Diameter, height, crown, and age relationship in eight neotropical tree species. Ecology 76.6: 1926-1939.

Oliver, Chadwick Dearing, and Bruce C. Larson (1996) Forest stand dynamics. John Wiley \& Sons, Inc.

Osler, G. H. R., P. W. West, and G. M. Downes (1996) Effects of bending stress on taper and growth of stems of young Eucalyptus regnans trees. Trees 10.4: 239-246.

Paillet, Frederick L. (2002) Chestnut: history and ecology of a transformed species. Journal of Biogeography 29.10-11: 1517-1530.

Parent, Jason R., and John C. Volin (2014) Assessing the potential for leaf-off LiDAR data to model canopy closure in temperate deciduous forests. ISPRS Journal of Photogrammetry and Remote Sensing 95: 134-145.

Peltola, Heli (1996) Swaying of trees in response to wind and thinning in a stand of Scots pine. Boundary-Layer Meteorology 77.3-4: 285-304.

Posada, Eva P. Roca, Juan G. Álvarez González, and Alberto Rojo Alboreca (2009) Windstorm damage in coniferous forests in Galicia (NW Spain) under different thinning treatments. Wind Effects on Trees 16: 283.

Poulos, H. M., and A. E. Camp (2010) Decision support for mitigating the risk of tree induced transmission line failure in utility rights-of-way. Environmental management 45.2: 217-226.

Rodriguez, Mathieu, Stéphane Ploquin, Bruno Moulia, and Emmanuel De Langre (2012) The multimodal dynamics of a walnut tree: experiments and models. Journal of Applied Mechanics 79.4: 044505. 
Roodbaraky, H. J., C. J. Baker, A. R. Dawson, and C. J. Wright (1994) Experimental observations of the aerodynamic characteristics of urban trees. Journal of Wind Engineering and Industrial Aerodynamics 52: 171-184.

Rudnicki, Mark, Uldis Silins, Victor J. Lieffers, and Georg Josi (2001) Measure of simultaneous tree sways and estimation of crown interactions among a group of trees. Trees 15.2: 83-90.

Rudnicki, Mark, Uldis Silins, and Victor J. Lieffers (2004) Crown cover is correlated with relative density, tree slenderness, and tree height in lodgepole pine. Forest Science 50.3: 356-363.

Rudnicki, Mark, Thomas H. Meyer, Victor J. Lieffers, Uldis Silins, and Vincent A. Webb (2008) The periodic motion of lodgepole pine trees as affected by collisions with neighbors. Trees 22.4: 475482.

Saunders, Denis A., Richard J. Hobbs, and Chris R. Margules (1991) Biological consequences of ecosystem fragmentation: a review. Conservation biology 5.1: 18-32.

Schindler, Dirk, Jochen Schönborn, Hannes Fugmann, and Helmut Mayer (2013) Responses of an individual deciduous broadleaved tree to wind excitation. Agricultural and forest meteorology 177:69-82.

Sellier, Damien, and Thierry Fourcaud (2005) A mechanical analysis of the relationship between free oscillations of Pinus pinaster Ait. saplings and their aerial architecture. Journal of experimental botany 56.416: 1563-1573.

Sellier, Damien, and Thierry Fourcaud (2009) Crown structure and wood properties: influence on tree sway and response to high winds. American Journal of Botany 96.5: 885-896.

Seymour, Robert S., and Alan S. White (2002) Natural disturbance regimes in northeastern North America-evaluating silvicultural systems using natural scales and frequencies. Forest Ecology and Management 155.1: 357-367.

Spatz, Hanns-Christof, Franka Brüchert, and Jochen Pfisterer (2007) Multiple resonance damping or how do trees escape dangerously large oscillations?. American Journal of Botany 94.10: 1603-1611.

Spatz, Hanns-Christof, and Benoit Theckes. "Oscillation damping in trees." Plant science 207 (2013): 6671.

Stull, R. B. (1988) An Introduction to Boundary Layer Meteorology. Kluwer Academic Publishers Dordrecht.

Telewski, Frank W. (1995) Wind-induced physiological and developmental responses in trees. In: Wind and trees, Cambridge University Press, Cambridge, pp. 237-263.

Telewski, Frank W. (2006) A unified hypothesis of mechanoperception in plants. American Journal of Botany 93.10:1466-1476. 
Theckes, Benoit, Emmanuel De Langre, and Xavier Boutillon. "Damping by branching: a bioinspiration from trees." Bioinspiration \& biomimetics 6.4 (2011): 046010.

Trenberth, Kevin E. (2011) Changes in precipitation with climate change. Climate Research 47.1-2: 123138.

United Illuminating Company (2013) Vegetation Management Plan: Distribution Planned Cycle. http://environment.yale.edu/uri/files/UI-vegetation-management-plan.pdf. Accessed 09-09-2016.

US Census Bureau (2010) Resident Population Data: Population Density. http://www .census.gov/2010census/data/apportionment-dens-text.php. Accessed 09-09-2016.

Vogel, Steven (1989) Drag and reconfiguration of broad leaves in high winds. Journal of Experimental Botany 40.8: 941-948.

Vogel, Steven (1996) Blowing in the wind: storm-resisting features of the design of trees. J. arboriculture 22: 92-98.

Wang, Yue, Stephen J. Titus, and Valerie M. LeMay (1998) Relationships between tree slenderness coefficients and tree or stand characteristics for major species in boreal mixedwood forests. Canadian Journal of Forest Research 28.8: 1171-1183.

Webb, Vincent A., Mark Rudnicki, and Shravan Kumar Muppa (2013) Analysis of tree sway and crown collisions for managed Pinus resinosa in southern Maine. Forest ecology and management 302: 193-199.

Webster, Peter J., Greg J. Holland, Judith A. Curry, and H-R. Chang (2005) Changes in tropical cyclone number, duration, and intensity in a warming environment. Science 309.5742: 1844-1846.

Wharton, Eric H., Richard H. Widmann, Carol L. Alerich, Charles H. Barnett, Andrew J. Lister, Tonya W. Lister, Don Smith, and Fred Borman (2004) The forests of Connecticut. US Department of Agriculture, Forest Service, Northeastern Research Station.

Wilson, Emily, Chester Arnold, John Volin (2015) Connecticut's Changing Landscape: A study of landcover change in Connecticut, 1985 - 2010. UCONN CLEAR. http://clear3.uconn.edu/viewers/ctstory/. Accessed 05-30-2017.

Wood, C. J. (1995) Understanding wind forces on trees. In: Wind in trees, Cambridge University Press, Cambridge, pp. 133-163.

Zhu, Jiao-Jun, Feng-Qi Jiang, and Matsuzaki Takeshi (2002) Spacing interval between principal tree windbreaks-Based on the relationship between windbreak structure and wind reduction. Journal of Forestry Research 13.2: 83-90. 